\title{
Rice Pest Constraints in Tropical Asia: Characterization of Injury Profiles in Relation to Production Situations
}

\author{
Serge Savary and Laetitia Willocquet, ORSTOM-IRRI Project on Rice Pest Characterization, International Rice \\ Research Institute, MCPO Box 3127, Makati City 1271, Philippines; Francisco A. Elazegui and Paul S. Teng, IRRI, \\ Entomology and Plant Pathology Division, Philippines; Pham Van Du, Cuu Long Rice Research Institute, Omon, \\ Cantho, Vietnam; Defeng Zhu, Qiyi Tang, Shiwen Huang, and Xianquing Lin, China National Rice Research \\ Institute, No. 359 Tiyuchang Road, Hangzhou 310006, Zhejiang, China; H. M. Singh and R. K. Srivastava, Narendra \\ Deva University of Agriculture and Technology, Narendra Nagar, PO Kumarganj, Faizabad, 224229 U.P., India
}

\begin{abstract}
Savary, S., Willocquet, L., Elazegui, F. A., Teng, P. S., Du, P. V., Zhu, D., Tang, Q., Huang, S., Lin, X., Singh, H. M., and Srivastava, R. K. 2000. Rice pest constraints in tropical Asia: Characterization of injury profiles in relation to production situations. Plant Dis. 84:341-356.

A protocol for characterizing patterns of rice cropping practices and injuries due to pathogens, insects, and weeds was developed and used in six sites in tropical Asia covering a wide range of environments where lowland rice is cultivated. The data collected in a total population of 456 individual farmers' fields were combined to site-specific weather data and analyzed using nonparametric multivariate techniques: cluster analyses with chi-square distance and correspondence analyses. The main results are: (i) patterns of cropping practices that are common across sites can be identified; (ii) conversely, injury profiles that are common across sites can be determined; (iii) patterns of cropping practices and injury profiles are strongly associated at the regional scale; (iv) weather patterns are strongly associated with patterns of cropping practices and injury profiles; (v) patterns of cropping practices and injury profiles allow for a good description of the variation in actual yield; and (vi) patterns of cropping practices and injury profiles provide a framework that accurately reflects weather variation and site diversity, and reliably accounts for variation in yield. The mean estimated yield across sites $\left(4.12 \mathrm{t} \mathrm{ha}{ }^{-1}\right)$ corresponds to commonly cited averages in the region and indicates the potential for increased productivity with better management practices, especially an improved water supply. Injuries due to pests are secondary compared with other yield-limiting factors. Injury profiles were dominated by stem rot and sheath blight (IN1); bacterial leaf blight, plant hoppers, and leaf folder (IN2); and sheath rot, brown spot, leaf blast, and neck blast (IN3). IN1 was associated with high (mineral) fertilizer inputs, long fallow periods, low pesticide use, and good water management in (mostly) transplanted rice crops of a rice-rice rotation. IN2 was associated with direct-seeded rice crops in an intensive rice-rice rotation, where fertilizer and pesticide inputs are low and water management is poor, or where fertilizer and pesticide inputs are high and water management is adequate. IN3 corresponds to low input, labor intensive (hand weeding and transplanting) rice crops in a diverse rotation system with uncertain water supply. Weed infestation was an omnipresent constraint. This study shows the potential for developing pest management strategies that can be adapted throughout the region, rather than being site-specific.
\end{abstract}

Additional keywords: cluster analysis, correspondence analysis, crop management, cropping system, multiple pest system

The past three decades have witnessed considerable changes in the way rice is being produced in tropical Asia. The avail-

Corresponding author: Serge Savary

E-mail: Serge.Savary@mpl.ird.fr

Current address of S. Savary and L. Willocquet: IRD, Institut de Recherche pour le Développement (formerly ORSTOM), 911, Ave. Agropolis, BP 5045, 34032 Montpellier cedex, France.

Accepted for publication 5 November 1999.

Publication no. D-2000-0105-01S

(C) 2000 The American Phytopathological Society technologies-especially irrigation, introduction of high-yielding varieties, fertilizer management, and pest management-interact in their yield-enhancing effects. These technologies have not been used in the same way, with the same intensity, and have acted on very different agroecological and social backgrounds across the region. The resulting picture is a complex one, where it is difficult to isolate and quantify the contribution of each technology on yield variation. From a plant protection perspective, these changes have led to shifts in the importance of rice diseases, insect pests, and weeds (19) that must be documented.

Over the past 10 years, a project on characterization of rice pests in tropical Asia has been conducted $(9,25,26)$ with the aims of assessing their importance and of determining the areas (both physical and scientific) where pest management has had, and will have, the largest impact. Surveys of farmers' fields give baseline information to assess the importance of pests. This report presents a synthesis of this survey work.

By and large, the concepts used here are derived from Rabbinge (22) and Van Ittersum and Rabbinge (36). We concentrate on actual yields measured in a population of lowland rice fields in tropical Asia and on relationships between variation in actual yield and yield-limiting (weather, irrigation, nutrient, and crop husbandry practices) and yield-reducing factors (pathogens, weeds, and insects). We characterize the production situation of each field, that is, the set of factors-physical, biological, and socioeconomic - that determine agricultural production $(7,22)$. The latter group of (socioeconomic) variables is assumed to be indirectly reflected by several characteristics of the patterns of cropping practices, such as inputs (fertilizers and pesticides), the method of crop establishment, weed control practices, and crop rotation.

More specifically, this analysis aims to (i) provide an overview of the distribution of rice pest injuries in six sites in tropical Asia; (ii) characterize the production 
situations (weather and cropping practices) under which rice production takes place; (iii) identify a set of typical injury profiles or combinations of rice pest injuries; (iv) analyze the relationships between production situations and injury profiles; and (v) assess the accuracy of the above characterizations in describing actual variation in yield.

\section{MATERIALS AND METHODS}

Selection of sites. Six sites were selected in which to conduct the survey: (i) the plain of Central Luzon, Philippines (CLUZ), where rice is cultivated under irrigated, relatively intensive conditions twice a year; (ii) the eastern coastal plain of Ilo-Ilo Island, Philippines (ILO), where rice cultivation is mostly rainfed, with low input; (iii) the inland plain of Laguna, Philippines (LAG), with well-tended, irrigated rice crops twice a year; (iv) the eastern part of Uttar Pradesh, India (FAIZ), on the Indo-Gangetic plains of South Asia, where rice is generally cultivated under rainfed conditions at very low levels of input, except labor, in a complex cropping system involving at least eight different major crops in rotation with rice; (v) the plains bordering the Yang Tse Delta in the Zhejiang Province of China (HGZ), where rice is intensively cultivated twice a year in a complex cropping system involving rapeseed, barley, and wheat; and (vi) the Mekong Delta, Vietnam (MD), with an intensive cropping system with three rice crops each year. Each of these sites can be seen as a specific reflection of the changes that accompany major agricultural transformations such as the green revolution, mirrored by local needs and constraints. These sites were selected in order to reflect such a diversity in agricultural change. Details on field selection within each site are given in the "Survey Portfolio" developed in this project $(25,27,30)$.

Sampling and data collection in each field. The survey was conducted in the rainy and dry seasons of 1987 in CLUZ; in the rainy seasons of 1992 and 1993 in FAIZ; in the winter, dry, and rainy seasons of 1996 in MD; in the rainy season of 1996 in ILO; in the dry and rainy seasons of 1996 in LAG; and in the early spring season of 1997 in HGZ. A total of 456 individual fields were surveyed in the six sites. Two broad types of data were gathered: (i) predominantly time-independent and qualitative information, i.e., location, previous crop, crop establishment method, rice variety, field operations, chemical input (fertilizers, pesticides), and yield; and (ii) time-dependent, quantitative information on crop growth and levels of injuries due to pests (pathogens, insects, and weeds). While the first group of field attributes was gathered from discussions with farmers and from direct field observation, the second group was derived from a specific, field-tested sampling design (9). The sec- ond group of field attributes (injuries) results from observations at four development stages of the growing crop: tillering, booting, early dough, and maturity. Except for weeds, information pertaining to injuries was collected in the form of number of injured organs (tillers, leaves, and panicles), which later was made relative to the corresponding total number of organs present in the sampling units (10 hills or $10 x$ $10 \mathrm{~cm}$ quadrats per field for transplanted or direct-seeded rice crops, respectively). In the case of weeds, the proportion of soil area covered at two levels of the crop canopy (below or above it) was assessed in three spots of $1 \mathrm{~m}^{2}$ each. Weather data were collected at standard weather stations at the center of, or as near as possible to, the surveyed field sites.

Nature and list of variables of the survey. Survey variables are listed in Table 1 within four groups: cropping practices, injuries, weather variables, and actual yield estimates. Simplifications and data compaction $(25,28)$ were necessary to achieve the objective of the analysis. A first set of simplifications pertains to the patterns of cropping practices. For instance, only the accumulated amount of chemical $(\mathrm{N}, \mathrm{P}$, and $\mathrm{K}$ ) fertilizer was used to represent input of chemical fertilizers, and not the individual inputs of $\mathrm{N}, \mathrm{P}$, and $\mathrm{K}$. The methods of crop establishment in rice are extremely diverse in Asia. Only two broad categories were considered: transplanted or direct-seeded. Likewise, three categories of weed control were considered: those that involve some hand weeding and therefore imply availability and use of labor as input, those that rely only on herbicides, and indirect (or unspecified) methods.

Injury variables were also simplified. Although a very large number of pathogens, insects, and weeds are harmful to rice $(18,21,31,33)$, many are seldom considered to cause yield losses. Diseases such as narrow brown spot, bacterial leaf streak, leaf scald, and leaf smut, and insects such as rice bugs, rice hispa, and defoliators in general are not considered to represent major, widespread, yield-reducing factors $(18,31,32,33)$. The study therefore concentrated on injuries listed in Table 1. A second aspect pertains to the injury mechanisms $(3,24)$, and Table 1 includes injuries that were grouped in the field assessment procedure according to their nature: light stealers (BLB, BS, LB: proportion of injured leaves), senescence accelerators (BLB, SHB, LB: proportion of injured leaves, except for SHB), tissue users (leaves: RWM, LF: proportion of injured leaves; tillers: SR, SHB, DH: proportion of injured tillers; panicles: SHR, WH: proportion of injured panicles), assimilate sappers (PH: number of insects sampled), turgor reducers (at the tiller level: SR, SHB: proportion of injured tillers; at the panicle level: NB: proportion of injured panicles), and stand reducers (WA and
WB: percent ground coverage; RTD: proportion of diseased hills or quadrats). Each injury was represented by varieties that would best represent its effect over time on the physiology of the crop. Broadly, two types of injury indices (25) were used: areas under progress curves or maximum level at any of the four observation dates, depending on the nature of the injury (Table 1; 25,27). The time-dependent information on injuries was thus synthesized and compacted over time.

The weather variables consisted of the mean daily maximum (TX) and minimum temperature $(\mathrm{TN})$, the mean daily radiation (RAD), and the accumulated rainfall (RAIN) during the rice cropping season. Variation in these values within a site was accounted for by the standard deviation of each variable (SD).

The variables listed in Table 1 show several differences: some are quantitative, but a few are, in essence, qualitative. The quantitative variables are expressed in different units; more importantly, the attributes pertain to different levels of organization: while the weather variables refer to the physical environment of an entire season in a site, cropping practices pertain to the population of rice plants in a crop, injuries refer to particular plant organs, and yield represents one output of a field seen as a system. The analytical steps used here stem to a large extent from these differences.

General analytical approach and hypotheses. The issue of observation and analysis scales is central to this study. While the information gathered pertains to the individual field, analysis of the data should aim at conclusions that have relevance to the region. A starting point for reflection is the uniqueness of each farmer's field, seen as an individual system described by a series of attributes, some of which are quantitative, while others are qualitative, ordinal, or cardinal (i.e., nonranked) variables (such as the method of crop establishment). The technical details of the survey methodology $(9,25,27,30)$ and of most of the analytical techniques used here (28) have been reported earlier.

A first question is the existence and strength of linkages between patterns of cropping practices and injuries. Therefore, a first null hypothesis tested, $\mathrm{H}_{01}$, is: "There is no linkage between cropping practices and injuries." In a second stage, the relationships between cropping practices and injuries in determining actual yields are explored. Thus, a second null hypothesis, $\mathrm{H}_{02}$, is: "Variation in actual yield cannot simply be accounted for by the simultaneous, sole consideration of cropping practices and injuries." A third issue addressed in this report is the general value of conclusions and their potential for extrapolation at a regional scale. This can be translated in a third null hypothesis, $\mathrm{H}_{03}$ : "All conclusions derived from surveys 
are specific to the sites where the data were collected."

Data analysis. The data collected were analyzed in steps. First, the quantitative variables were categorized into classes (Table 2). They thus became ordinal (e.g., low, medium, high), qualitative variables, while variables such as "weed control practices" (WCP) remained cardinal, qualitative variables. Table 2 shows the numerical boundaries and classes that were created. The number of categories was made as small as possible for all variables, in order to ensure a class-filling as regular as possible, and the numerical boundaries were chosen so as to have each class represented by commensurate numbers of individual fields $(17,28)$. Regular and suffi- cient filling of each class determines the expected size of each class in chi-square tests, a prerequisite to their validity $(6,11)$. All injuries were categorized in three classes, and the boundaries were chosen depending on each of their respective distribution frequencies. Five successive yield classes were defined, in order to enable a better description and analysis of variation of actual yield, from very low (Y1) to very high yield levels (Y5).

Chi-square tests were performed using this coded, categorized information. The tests pertained either to the same level of organization (e.g., relationships among paired injuries), or to adjacent levels of organization (e.g., relationships between patterns of cropping practices and yield or injuries and yield). Some of these tests are briefly reported here.

Next, cluster analyses using a nearest neighbor and a chi-square distance (15) were performed in subsets representing each site, in order to determine site-specific patterns of cropping practices and injury profiles. Clusters including less than $n=3$ fields were disregarded from further steps.

The site-specific clusters for patterns of cropping practices and injuries were then considered separately. The modes (for qualitative variables) and the medians (for quantitative ones) of each variable representing individual fields within each of these two types of clusters were computed. Two sets of field ideotypes were thus generated to represent either site-specific

Table 1. List of variables describing individual fields in surveys of rice injuries in six sites in tropical Asia

\begin{tabular}{|c|c|c|c|}
\hline Variable type & Symbol & Variable description & Unit \\
\hline \multicolumn{4}{|c|}{ Cropping practices } \\
\hline & MF & Total mineral fertilizer supply to the rice crop & $\mathrm{kg} \mathrm{ha}^{-1}$ \\
\hline & FP & Fallow period duration preceding the rice crop & Days \\
\hline & WCP & Weed control practices & (None) \\
\hline & $\mathrm{IU}$ & Insecticide use in number of applications & Number \\
\hline & HU & Herbicide use in number of applications & Number \\
\hline & FU & Fungicide use in number of applications & Number \\
\hline & DS & Accumulated drought stress (number of observed occurrences ${ }^{a}$ ) & Number, 0 to 4 \\
\hline & WE & Accumulated water excess (number of observed occurrences a) & Number, 0 to 4 \\
\hline & PM & Planting method (transplanted or direct-seeded) & (None) \\
\hline & $\mathrm{PC}$ & Crop preceding rice in the same field & (None) \\
\hline \multicolumn{4}{|c|}{ 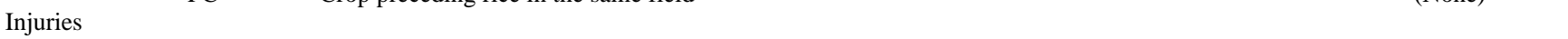 } \\
\hline & BLB & $\begin{array}{l}\text { Area under the progress curve of mean percentage of leaves with bacterial leaf blight symptoms ( } 4 \\
\text { visits }^{b} \text { ) }\end{array}$ & $\left(\% \mathrm{dsu}^{\mathrm{c}}\right)$ \\
\hline & SR & Maximum percentage of tillers with stem rot symptoms & $(\%)$ \\
\hline & SHR & Maximum percentage of panicles with sheath rot symptoms & $(\%)$ \\
\hline & SHB & Maximum percentage of tillers with sheath blight symptoms & $(\%)$ \\
\hline & BS & Area under the progress curve of mean percentage of leaves with brown spot symptoms (4 visits) & $(\% \mathrm{dsu})$ \\
\hline & LB & Area under the progress curve of mean percentage of leaves with leaf blast symptoms (4 visits) & $(\% \mathrm{dsu})$ \\
\hline & NB & Maximum percentage of panicles with neck blast symptoms & $(\%)$ \\
\hline & RTD & Maximum percentage of hills or quadrats with rice tungro disease symptoms & $(\%)$ \\
\hline & $\mathrm{PH}^{\mathrm{d}}$ & Area under the progress curve of number of plant hoppers caught per hill of sampled quadrat (4 visits) & (Number dsu) \\
\hline & RWM & Area under the progress curve of mean percentage of leaves with whorl maggot injury (4 visits) & (\% dsu) \\
\hline & LF & Area under the progress curve of mean percentage of leaves with leaf folder injury (4 visits) & $(\% \mathrm{dsu})$ \\
\hline & DH & Maximum percentage of tillers with dead heart (stem borer) injury & $(\%)$ \\
\hline & WH & Maximum percentage of panicles with white head (stem borer) injury & $(\%)$ \\
\hline & WA & $\begin{array}{l}\text { Area under the progress curve of percent weed infestation (ground coverage) above the crop canopy ( } 4 \\
\text { visits) }\end{array}$ & $(\% \mathrm{dsu})$ \\
\hline & WB & $\begin{array}{l}\text { Area under the progress curve of percent weed infestation (ground coverage) below the crop canopy ( } 4 \\
\text { visits) }\end{array}$ & $(\% \mathrm{dsu})$ \\
\hline \multicolumn{4}{|c|}{ VISIS) } \\
\hline & TX & Mean maximum daily temperature during the cropping season & $\left({ }^{\circ} \mathrm{C}\right)$ \\
\hline & TXSD & Standard deviation of the mean maximum temperature during the cropping season & $\left({ }^{\circ} \mathrm{C}\right)$ \\
\hline & $\mathrm{TN}$ & Mean minimum daily temperature during the cropping season & $\left({ }^{\circ} \mathrm{C}\right)$ \\
\hline & TNSD & Standard deviation of the mean minimum temperature during the cropping season & $\left({ }^{\circ} \mathrm{C}\right)$ \\
\hline & RAD & Mean daily radiation during the cropping season & $\left(\mathrm{MJ} \mathrm{m}^{-2}\right)$ \\
\hline & RADSD & Standard deviation of the mean daily radiation during the cropping season & $\left(\mathrm{MJ} \mathrm{m}^{-2}\right)$ \\
\hline & RAIN & Accumulated rainfall during the cropping season & $(\mathrm{mm})$ \\
\hline & RAINSD & Standard deviation of the daily rainfall during the cropping season & $(\mathrm{mm})$ \\
\hline \multicolumn{4}{|c|}{ 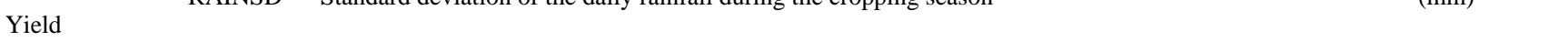 } \\
\hline & $\mathrm{Y}$ & Estimated yield (grain yield, $14 \%$ moisture) from 3 crop cuts $10 \mathrm{~m}^{2}$ each & $\left(\mathrm{t} \mathrm{ha}^{-1}\right)$ \\
\hline \multicolumn{4}{|c|}{ 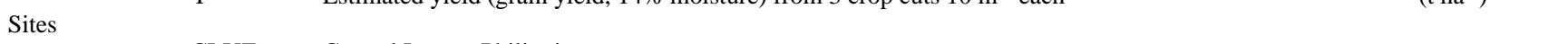 } \\
\hline & CLUZ & Central Luzon, Philippines & \\
\hline & FAIZ & Faizabad, Uttar Pradesh, India & \\
\hline & HGZ & Hangzhou, Zhejiang, China & \\
\hline & ILO & Ilo-Ilo, Philippines & \\
\hline & LAG & Laguna, Philippines & \\
\hline & MD & Mekong Delta, Vietnam & \\
\hline
\end{tabular}

a Accumulated number of observed occurrences over four visits during the crop cycle.

${ }^{\mathrm{b}}$ Assessments in each field were done at the tillering, booting, early dough, and maturity stages.

${ }^{c}$ dsu: development stage units on a 0 to 100 scale.

${ }^{d} \mathrm{PH}$ combines the brown plant hopper, white back plant hopper, and zig-zag plant hopper.

${ }^{\mathrm{e}}$ Weather variables were gathered at the nearest weather station, usually at the center of each survey site. 
clusters of cropping practices (PR SITE no.) or site-specific clusters of injuries (IN SITE no.). These field ideotypes were used for the next cluster analyses to represent their corresponding site-specific clusters of cropping practices and of injuries. Two independent final cluster analyses were performed on these two sets of ideotypes using the same algorithm. These yielded meta-clusters of cropping practices and of injuries that might or might not be common across sites. Cluster analysis was also applied to categorized weather data representing all combinations of sites and seasons to generate weather patterns.

Cluster analyses thus generated three synthetic and qualitative variables: the clusters of cropping practices (PR), of injury profile (IN), and of weather (W) to which a given field belongs. These three variables were then used in the final stage of the analysis, along with actual yield levels: chi-square tests were performed to assess relationships among these variables, and correspondence analyses $(2,12,15,16,28)$ were performed.

Correspondence analysis was first applied to three such contingency tables: [PR $\times$ IN] (corresponding to hypothesis $\mathrm{H}_{01}$ ), $[\mathrm{PR} \times \mathrm{Y}]$, and $[\mathrm{IN} \times \mathrm{Y}]$. The two latter contingency tables, their associated chisquare tests, and correspondence analyses represent further testing of the clusterings made for patterns of cropping practices and injury profiles and their relevance in describing the variation in actual yield, which was not involved in cluster analyses.

Applying production ecology concepts $(22,36)$ where attainable yields are reduced to actual yield levels by injuries, yieldlimiting factors (accounted for by cropping practices and synthesized into the PR classes), and yield-reducing factors (IN classes) were used to describe actual yield variation. This approach aims at testing $\mathrm{H}_{03}$, i.e., addressing the generalization value of the analysis and the potential to extrapolate results at a regional scale. It was based on the construction of a Burt table (16), i.e., a matrix where the $[\mathrm{PR} \times$ $\mathrm{IN}]$ and $[\mathrm{IN} \times \mathrm{PR}]$ contingency tables are

Table 2. Categorization of variables describing individual fields in surveys of rice injuries in six sites in tropical Asia

\begin{tabular}{|c|c|c|c|}
\hline Variable type & Symbol $^{\mathbf{a}}$ & Categories & Category definition ${ }^{b}$ \\
\hline \multicolumn{4}{|c|}{ Cropping practices } \\
\hline & MF & MF0, MF1, MF2, MF3 & $\begin{array}{l}\text { MF0: MF }=0 \mathrm{~kg} \mathrm{ha}^{-1} ; \text { MF1: } 0<\mathrm{MF} \leq 50 \mathrm{~kg} \mathrm{ha}^{-1} ; \mathrm{MF} 2: 50<\mathrm{MF} \leq 140 \mathrm{~kg} \mathrm{ha}^{-1} ; \mathrm{MF} 3: 140< \\
\mathrm{MF} \leq 300 \mathrm{~kg} \mathrm{ha}^{-1}\end{array}$ \\
\hline & FP & FP1, FP2, FP3, FP4 & $\begin{array}{l}\text { FP1: FP } \leq 15 \text { days; FP2: } 15<\text { FP } \leq 40 \text { days ; FP3: } 40<\text { FP } \leq 100 \text { days; FP4: } 100<\text { FP } \leq 350 \\
\text { days }\end{array}$ \\
\hline & WCP & NW, Hand, Herb & $\begin{array}{l}\text { NW: no direct weed control practice used; Hand: some hand weeding; Herb: exclusive } \\
\text { reliance on herbicides }\end{array}$ \\
\hline & IU & IU0, IU1, IU2 & $\begin{array}{l}\text { IU0: no insecticide application; IU1: one insecticide application; IU2: two insecticide } \\
\text { applications or more }\end{array}$ \\
\hline & $\mathrm{HU}$ & HU0, HU1, HU2 & $\begin{array}{l}\text { HU0: no herbicide application; HU1: one herbicide application; HU2: two herbicide } \\
\text { applications or more }\end{array}$ \\
\hline & FU & FU0, FU1 & FU0: no fungicide application; FU1: one fungicide application or more \\
\hline & DS & DS1, DS2, DS3 & DS1: $0 \leq \mathrm{DS} \leq 1 ; \mathrm{DS} 2: 1<\mathrm{DS} \leq 2 ; \mathrm{DS} 3: 2<\mathrm{DS} \leq 4$ \\
\hline & WE & WE0, WE1 & WE0: $W E=0 ;$ WE1: $0<\mathrm{WE} \leq 4$ \\
\hline & PM & TR, DS & TR: transplanting; DS: direct seeding \\
\hline & $\mathrm{PC}$ & Rice, Fal, Leg, W/B, Misc. & $\begin{array}{l}\text { Rice: rice as previous crop; Fal: fallow period exceeding } 140 \text { days; Leg: Legume crop; W/B: } \\
\text { Wheat or Barley; Misc: miscellaneous crops }\end{array}$ \\
\hline \multicolumn{4}{|r|}{ 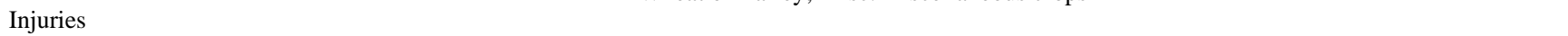 } \\
\hline & BLB & BLB0, BLB1, BLB2 & BLB0: $\mathrm{BLB}=0 \%$ dsu; BLB1: $0<\mathrm{BLB} \leq 20 \%$ dsu; BLB2: $20<\mathrm{BLB} \leq 2,000 \%$ dsu \\
\hline & SR & SR0, SR1, SR2 & $\mathrm{SR} 0: \mathrm{SR}=0 \% ; \mathrm{SR} 1: 0<\mathrm{SR} \leq 1 \% ; \mathrm{SR} 2: 1<\mathrm{SR} \leq 30 \%$ \\
\hline & SHR & SHR0, SHR1, SHR2 & SHR0: SHR $=0 \%$; SHR $1: 0<$ SHR $\leq 3 \%$; SHR $2: 3<$ SHR $\leq 50 \%$ \\
\hline & SHB & SHB0, SHB1, SHB2 & SHB0: $\mathrm{SHB}=0 \%$; SHB $1: 0<\mathrm{SHB} \leq 5 \% ;$ SHB $2: 5<$ SHB $\leq 50 \%$ \\
\hline & BS & BS0,BS1, BS2 & BS0: $\mathrm{BS}=0 \%$ dsu; $\mathrm{BS} 1: 0<\mathrm{BS} \leq 100 \%$ dsu; $\mathrm{BS} 2: 100<\mathrm{BS} \leq 4,000 \%$ dsu \\
\hline & LB & LB0, LB1, LB2 & LB0: LB $=0 \%$ dsu; LB1: $0<$ LB $\leq 20 \%$ dsu; LB2: $20<$ LB $\leq 3,000 \%$ dsu \\
\hline & NB & NB0, NB1, NB2 & $\mathrm{NB} 0: \mathrm{NB}=0 \% ; \mathrm{NB} 1: 0<\mathrm{NB} \leq 5 \% ; \mathrm{NB} 2: 5<\mathrm{NB} \leq 70 \%$ \\
\hline & $\mathrm{PH}^{\mathrm{c}}$ & PH0, PH1, PH2 & PH0: $\mathrm{PH}=0 \mathrm{~N}$ dsu; $\mathrm{PH} 1: 0<\mathrm{PH} \leq 50 \mathrm{~N}$ dsu; $\mathrm{PH} 2: 50<\mathrm{PH} \leq 400 \mathrm{~N}$ dsu \\
\hline & RWM & RWM0, RWM1, RWM2 & $\begin{array}{l}\text { RWM0: RWM }=0 \% \text { dsu; RWM1: } 0<\text { RWM } \leq 100 \% \text { dsu; RWM2: } 100<\text { RWM } \leq 1,200 \% \\
\text { dsu }\end{array}$ \\
\hline & LF & LF0, LF1, LF2 & LF0: $L F=0 \%$ dsu; LF1: $0<\mathrm{LF} \leq 100 \%$ dsu; $\mathrm{LF} 2: 100<\mathrm{LF} \leq 2,500 \%$ dsu \\
\hline & DH & DH0, DH1, DH2 & $\mathrm{DH} 0: \mathrm{DH}=0 \%$; DH1: $0<\mathrm{DH} \leq 5 \% ; \mathrm{DH} 2: 5<\mathrm{DH} \leq 40 \%$ \\
\hline & WH & WH0, WH1, WH2 & WH0: $\mathrm{WH}=0 \%$; WH1: $0<\mathrm{WH} \leq 5 \%$; WH2: $5<\mathrm{WH} \leq 30 \%$ \\
\hline & WA & WA1, WA2, WA3 & $\begin{array}{l}\text { WA1: } 0 \leq \text { WA } \leq 200 \% \text { dsu; WA2: } 200<\text { WA } \leq 1,000 \% \text { dsu; WA3: } 1,000<\text { WA } \leq 3,500 \% \\
\text { dsu }\end{array}$ \\
\hline & WB & WB1, WB2, WB3 & $\begin{array}{l}\text { WB1: } 0 \leq \mathrm{WB} \leq 200 \% \text { dsu; WB2: } 200<\mathrm{WB} \leq 1,000 \% \text { dsu; WB3: } 1,000<\mathrm{WB} \leq 4,000 \% \\
\text { dsu }\end{array}$ \\
\hline \multicolumn{4}{|l|}{ Climate } \\
\hline & TX & TX1, TX2, TX3 & $\mathrm{TX} 1: \mathrm{TX} \leq 31^{\circ} \mathrm{C} ; \mathrm{TX} 2: 31<\mathrm{TX} \leq 32^{\circ} \mathrm{C} ; \mathrm{TX} 3: 32<\mathrm{TX} \leq 35^{\circ} \mathrm{C}$ \\
\hline & TXSD & TXSD1, TXSD2, TXSD3 & TXSD1: $\mathrm{TXSD} \leq 1.4^{\circ} \mathrm{C} ; \mathrm{TXSD} 2: 1.4<\mathrm{TXSD} \leq 1.8^{\circ} \mathrm{C} ; \mathrm{TXSD} 3: 1.8<\mathrm{TXSD} \leq 3.0^{\circ} \mathrm{C}$ \\
\hline & $\mathrm{TN}$ & TN1, TN2, TN3 & $\mathrm{TN} 1: \mathrm{TN} \leq 22^{\circ} \mathrm{C} ; \mathrm{TN} 2: 22<\mathrm{TN} \leq 24^{\circ} \mathrm{C} ; \mathrm{TN} 3: 24<\mathrm{TN} \leq 30^{\circ} \mathrm{C}$ \\
\hline & TNSD & TNSD1, TNSD2, TNSD3 & TNSD1: $\mathrm{TNSD} \leq 1.0^{\circ} \mathrm{C} ; \mathrm{TNSD} 2: 1.0<\mathrm{TNSD} \leq 2.0^{\circ} \mathrm{C} ; \mathrm{TNSD} 3: 2.0<\mathrm{TNSD} \leq 3.0^{\circ} \mathrm{C}$ \\
\hline & RAD & RAD1, RAD2, RAD3 & $\begin{array}{l}\text { RAD1: RAD } \leq 17.0 \mathrm{MJ} \mathrm{m}^{-2} ; \mathrm{RAD} 2: 17.0<\mathrm{RAD} \leq 20.0 \mathrm{MJ} \mathrm{m}^{-2} ; \mathrm{RAD} 3: 20.0<\mathrm{RAD} \leq 25.0 \\
\mathrm{MJ} \mathrm{m}^{-2}\end{array}$ \\
\hline & RADSD & $\begin{array}{l}\text { RADSD1, RADSD2, } \\
\text { RADSD3 }\end{array}$ & $\begin{array}{l}\text { RADSD1: RADSD } \leq 4.0 \mathrm{MJ} \mathrm{m}^{-2} ; \text { RADSD2: } 4.0<\text { RADSD } \leq 5.0 \mathrm{MJ} \mathrm{m}^{-2} ; \text { RADSD3: } 5.0< \\
\text { RADSD } \leq 8.0 \mathrm{MJ} \mathrm{m}^{-2}\end{array}$ \\
\hline & RAIN & RAIN1, RAIN2, RAIN3 & $\begin{array}{l}\text { RAIN1: RAIN } \leq 400 \text { mm; RAIN2: } 400<\text { RAIN } \leq 700 \text { mm; RAIN3: } 700<\text { RAIN } \leq 1,500 \\
\text { mm }\end{array}$ \\
\hline & RAINSD & $\begin{array}{l}\text { RAINSD1, RAINSD2, } \\
\text { RAINSD3 }\end{array}$ & $\begin{array}{l}\text { RAINSD1: RAINSD } \leq 5 \mathrm{~mm} \text {; RAINSD2: } 5<\text { RAINSD } \leq 15 \mathrm{~mm} \text {; RAINSD3:15 < RAINSD } \\
\leq 53 \mathrm{~mm}\end{array}$ \\
\hline Yield & $\mathrm{Y}$ & $\mathrm{Y} 1, \mathrm{Y} 2, \mathrm{Y} 3, \mathrm{Y} 4, \mathrm{Y} 5$ & $\begin{array}{l}\text { Y1: } \mathrm{Y}<2.75 \mathrm{t} \mathrm{ha}^{-1} ; \mathrm{Y} 2: 2.75 \leq \mathrm{Y}<3.75 \mathrm{tha}^{-1} ; \mathrm{Y} 3: 3.75 \leq \mathrm{Y}<4.25 \mathrm{tha}^{-1} ; \mathrm{Y} 4: 4.25 \leq \mathrm{Y}< \\
5.25 \mathrm{t} \mathrm{ha}^{-1} ; \mathrm{Y}^{2}: 5.25 \leq \mathrm{Y}<8.33 \mathrm{t} \mathrm{ha}^{-1}\end{array}$ \\
\hline
\end{tabular}

\footnotetext{
a Variables are listed in Table 1.
}

${ }^{\mathrm{b}}$ Categories for quantitative variables are defined by numerical boundaries.

${ }^{\mathrm{c}} \mathrm{N}$ dsu is the unit for area under the progress curve of number of plant hoppers caught per hill of sampled quadrat (4 visits). 
combined. Additional matrices, [Y $\times$ PR] and $[\mathrm{Y} \times \mathrm{IN}]$, were appended to this table, and correspondence analysis was conducted, considering the $\mathrm{Y}$ classes as additional variables. This amounts to identifying a series of axes based on patterns of cropping practices and injury profiles only and projecting on this system of axes the classes of yield levels. A simplified view of this last analysis is to consider PR and IN as explanatory variables and $\mathrm{Y}$ as the variable to be explained. Weather patterns and sites were also involved in this final analysis.

\section{RESULTS}

Prevalence of injuries across sites and seasons. Differences among sites and seasons for injury prevalence (percent fields affected by a given injury; 37 ) were summarized (Table 3). Among the injuries caused by pathogens, SHB showed the highest prevalence, exceeding $50 \%$ in any site-season combination. SHR, BS, and SR occurred in decreasing order of prevalence level. At the other end of this spectrum, RTD was observed in one site and one season only, and thus was not further considered in the analyses. Insect injuries appear to have higher prevalence than those due to pathogens. Most insect injuries were omnipresent, often with prevalence exceeding $80 \%$. Weed infestation, both above and below the rice crop canopy, was omnipresent and had the highest prevalence levels of all injuries. This crude summary also suggests that differences as well as similarities occurred among sites and seasons with respect to occurrence of injuries.

Characterization of climatic variation across sites and seasons. Cluster analysis led to the identification of six broad weather patterns (Fig. 1). While these patterns conform with current knowledge of tropical or subtropical climates in the re- gion (1), they provide information on specific weather characteristics pertaining to the sites and the seasons during which the survey took place. W1 has medium to high TX and TN, medium to high and variable RAD, and high RAIN. This group broadly corresponds to rainy seasons in the warm, humid tropics (Table 4). It includes rainy seasons in CLUZ, ILO, LAG, and MD. W2 is characterized by high RAD, medium TX and TN, and low RAIN. This group corresponds to cloudless dry season in the warm humid tropics (Table 4). It is represented by the dry season in CLUZ. W3 is mainly characterized by high TX and low to medium but highly variable RAIN. It is also associated with medium TN and low to medium RAD (Table 4). This group represents the rainy (kharif) season in the warm subarid tropics of southern Asia. It includes the rainy seasons in FAIZ. W4 corresponds to low TX and TN, as well as low RAD (Table 4). It also is associated with low to medium RAIN. This group represents dry but cloudy seasons in the warm humid tropics (LAG) or spring to early summer weather in the subtropical regions of eastern Asia (HGZ). W5 is mainly characterized by low RAIN combined with high TX, medium TN, and medium RAD (Table 4). It is represented by the "winter-spring" season of the Mekong Delta only, i.e., climatic conditions preceding the onset of the monsoon in the warm humid tropics of Asia. W6 is characterized by high TX and TN, medium RAD, and medium RAIN (Table 4). It is similar to W2, but with higher RAIN (and therefore lower RAD) and higher TX and TN. It represents another type of dry season in the warm humid tropics (MD, dry season).

Characterization of patterns of cropping practices. Six patterns of cropping practices were determined from cluster analyses (Fig. 2). PR1 corresponds to a rice-rice cropping system, where the rice crop is mostly transplanted, with relatively high input (mineral fertilizers and pesticides), a relatively long fallow period, and a good control of water supply (Table 5). PR1 accounts for the largest population of fields surveyed $(n=148)$ and is common to two sites (CLUZ and HGZ). PR2 is also a rice-rice transplanted system, but with lower input (mineral fertilizer, especially) and a poorer control of the water supply. Input in the form of labor, aside from transplanting, appears to be low, as suggested by the absence of specific weed control actions $(\mathrm{NW}=100 \%$, Table 5). This pattern is represented by six fields only in one site (CLUZ). PR3 accounts for rice crops in the "rice-wheat" system of southern Asia, with very diverse crops, including wheat, preceding rice. The inputs, especially pesticides, are very low, and the water control is poor. Weed control often involves hand weeding (Table 5; Hand $=89.3 \%$, the highest proportion among all clusters), reflecting input in the form of labor. The rice crop is mostly transplanted, but direct seeding occurs. This pattern is mostly found in one site (FAIZ), but also in another (ILO) that does not belong to the rice-wheat system but shares commonalties with it, with various crops preceding rice, low input, drought stress, and direct seeding. PR3 accounts for the second largest population of fields surveyed $(n=140)$. PR4 is characterized by very high input to the crop (fertilizer and pesticides), transplanting, some hand weeding, and a moderately good control of the water supply, in another rice-wheat system, with diverse crops such as barley, rapeseed, or wheat preceding rice. This group is represented in one site only (HGZ), with a small $(n=11)$ number of fields. PR5 represents rice crops in a rice-

Table 3. Prevalence of injuries ${ }^{\mathrm{a}}$ across sites and seasons

\begin{tabular}{|c|c|c|c|c|c|c|c|c|c|c|}
\hline \multirow{2}{*}{$\begin{array}{l}\text { Site } \\
\text { Season }\end{array}$} & \multicolumn{2}{|c|}{ CLUZ ${ }^{b}$} & \multirow{2}{*}{$\begin{array}{l}\text { FAIZc } \\
\text { Rainy }\end{array}$} & \multirow{2}{*}{$\begin{array}{c}\text { HGZ } \\
\text { Spring }\end{array}$} & \multirow{2}{*}{$\begin{array}{c}\text { ILO } \\
\text { Rainy }\end{array}$} & \multicolumn{2}{|c|}{ LAG } & \multicolumn{3}{|c|}{ MD } \\
\hline & Dry & Rainy & & & & Dry & Rainy & Dry & Rainy & Winter \\
\hline$n^{d}$ & 48 & 87 & 146 & 33 & 40 & 15 & 15 & 32 & 20 & 20 \\
\hline $\mathrm{BLB}^{\mathrm{e}}$ & 0 & 6.9 & 2.1 & 0 & 17.5 & 13.3 & 53.3 & 40.6 & 60.0 & 30.0 \\
\hline SR & 39.6 & 33.3 & 2.1 & 0 & 30.0 & 86.7 & 86.7 & 18.8 & 5.0 & 25.0 \\
\hline SHR & 20.8 & 0 & 71.9 & 54.5 & 100 & 86.7 & 73.3 & 75.0 & 45.0 & 20.0 \\
\hline SHB & 62.5 & 66.7 & 71.2 & 100 & 70.0 & 80.0 & 100 & 75.0 & 75.0 & 50.0 \\
\hline BS & 10.4 & 6.3 & 99.3 & 30.3 & 65.0 & 13.3 & 0 & 59.4 & 100 & 95.0 \\
\hline LB & 0.0 & 0.0 & 41.8 & 0.0 & 7.5 & 13.3 & 46.7 & 15.6 & 25.0 & 90.0 \\
\hline NB & 0.0 & 2.1 & 39.7 & 6.1 & 5.0 & 6.7 & 6.7 & 25.0 & 20.0 & 30.0 \\
\hline $\mathrm{PH}$ & 54.2 & 72.9 & 1.4 & 72.7 & 100 & 86.7 & 93.3 & 96.9 & 75.0 & 100 \\
\hline RWM & 100 & 93.8 & 86.3 & 0.0 & 100 & 100 & 100 & 87.5 & 100 & 80.0 \\
\hline LF & 100 & 100 & 98.6 & 45.5 & 95.0 & 100 & 100 & 100 & 70.0 & 100 \\
\hline $\mathrm{DH}$ & 77.1 & 70.8 & 72.6 & 66.7 & 100 & 86.7 & 93.3 & 46.9 & 55.0 & 80.0 \\
\hline WH & 95.8 & 89.6 & 87.0 & 54.5 & 100 & 86.7 & 93.3 & 18.8 & 35.0 & 20.0 \\
\hline WA & 100 & 93.8 & 80.8 & 97.0 & 97.5 & 93.3 & 93.3 & 100 & 95.0 & 85.0 \\
\hline WB & 100 & 97.9 & 77.4 & 100 & 97.5 & 100 & 100 & 100 & 95.0 & 65.0 \\
\hline RTD & 0.0 & 3.4 & 0.0 & 0.0 & 0.0 & 0.0 & 0.0 & 0.0 & 0.0 & 0.0 \\
\hline
\end{tabular}

${ }^{a}$ Percent surveyed fields affected in each site and cropping season.

b See Table 1 for list of sites.

c Two consecutive (rainy) seasons surveyed.

d Number of fields surveyed per site and season.

${ }^{\mathrm{e}}$ See Table 1 for list of injuries. 


\section{Derived Weather Pattern}

W1

Medium to high maximum daily temperature;

Very variable radiation;

\section{High maximum and minimum daily temperature Medium radiation: \\ W2 \\ Medium maximum and minimum daily temperature: High radiation; Low rainfall}

W5

High maximum and medium minimum daily temperature; Modium radia

W3

High maximum and minimum daily Low to medium radiation; Low to medium, and highly variable rainfal
W4

Low maximum and

minimum daily

Low radiation;

Low to medium rainfall
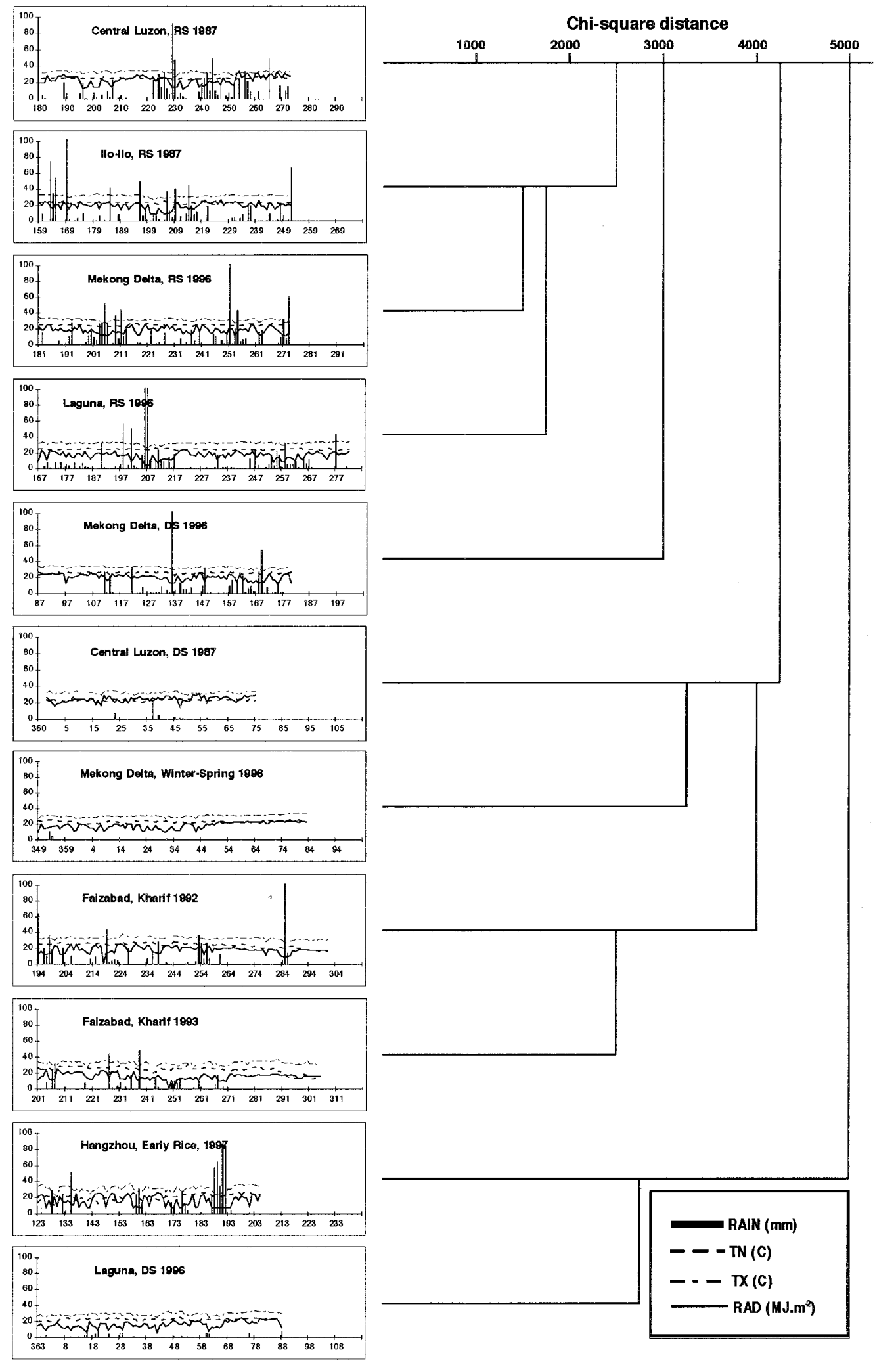

Time (Julian Daye)

Fig. 1. Cluster analysis of categorized (Table 2) weather data pertaining to various cropping seasons using a nearest neighbor method and a chi-square distance in six sites in tropical Asia. Six weather patterns are derived based on daily rainfall (RAIN), minimum daily temperature (TN), maximum daily temperature (TX), and daily radiation (RAD). 
rice system, with a relatively short fallow period, fairly high labor and chemical input, and often a poor control of the water supply. A majority of the fields of this group are direct seeded (Table 5). This group is represented by $n=81$ fields in three different sites (ILO, LAG, MD). PR6 is characterized by rice crops that are exclusively direct seeded in a very intensive rice monoculture with three crops per year, high input, and reasonably good water control. Direct weed control measures are replaced by extremely high seeding rates. Among these clusters, PR4 is associated with the highest yield level $\left(6.7 \mathrm{t} \mathrm{ha}^{-1}\right.$, Table 5), followed by PR1 (4.8 $\left.\mathrm{t} \mathrm{ha}^{-1}\right)$ and PR2 (4.6 t ha-1). The lowest yields are associated with PR3 (3.5 $\left.\mathrm{t} \mathrm{ha}^{-1}\right)$.

Characterization of injury profiles. Cluster analyses yielded five groups of injury profiles (Fig. 3), out of which three (IN1, IN2, and IN3) account for the bulk of the surveyed fields. Figure 3 also indicates the injury profiles corresponding to each cluster, with each injury represented as a percentage based on the highest cluster mean as a reference. The characteristics of the clusters are also summarized quantitatively in Table 6 . IN1 is characterized by comparatively high SR, SHB, PH, and RWM injuries, low BS, and absence of BLB, LB, and NB. This profile accounts for the largest population of fields $(n=$ 180). IN2 corresponds to presence of BLB, high BS, LB, RWM, and LF injuries. It is also characterized by high weed infestation, both above and below the rice crop canopy (WA and WB). This profile is represented by $n=108$ fields. IN3 is characterized by high SHR, BS, LB, NB, DH, and WH; low RWM and LF; and absence of BLB, SR, and PH. This profile is represented by $n=123$ fields. IN4 is characterized by high SHR, SHB, and WB; low RWM, LF, and DH; and absence of BLB, $\mathrm{SR}, \mathrm{LB}$, and PH. This profile accounts for $n=14$ fields. IN5 is characterized by overall low or null injury levels. Weed infestation (WA and WB) is particularly low in this injury profile, which is represented by four fields only. IN5 and IN3 are associated with the lowest mean yields (3.3 and $3.5 \mathrm{t} \mathrm{ha}^{-1}$, respectively, Table 6), while IN1 and IN4 are associated with the highest mean yields (4.6 and $4.3 \mathrm{t} \mathrm{ha}^{-1}$, respectively, Table 6).

Geographic distribution of weather patterns, cropping practices, and injury profiles. The geographic distribution of weather patterns is displayed in Figure 4A. Some patterns are common across sites (i.e., W1 in MD, ILO, CLUZ, and LAG, and W4 in HGZ and LAG). Some other weather patterns are site-specific, such as W3 (FAIZ). Figure 4B shows the geographic distribution of patterns of cropping practices. PR1 is found in two sites (HGZ and CLUZ), PR3 is also found in two sites (FAIZ, ILO), while PR5 is found in three sites (LAG, MD, and ILO). Conversely, some sites appear very homogeneous with respect to the patterns of cropping practices (FAIZ: PR3; LAG: PR5), while others are heterogeneous (MD, HGZ, ILO, with two patterns of cropping practices each). Figure $4 \mathrm{C}$ provides a geographic display of the distribution of the six injury profiles. IN2 appears to be the most common injury profile and is represented in four sites (CLUZ, ILO, LAG, and MD). IN1 is represented in three sites (HGZ, ILO, and CLUZ). IN3, IN4, and IN5 are represented in one site only, FAIZ. Conversely, FAIZ appears the most diverse, albeit specific, site with respect to injury profiles, while differing (but not site-specific) injury profiles are present in HGZ, CLUZ, and ILO.

Linkages among clusters of weather types, cropping practices, injuries, and yield levels. Strong linkages were found among most of the clusters of weather types, cropping practices, and injuries, as well as with sites and yield levels. In all tests, only clusters with a minimum sample size of $n=30$ were considered in order to achieve large expected values. The clusters of cropping practices and injury profiles were therefore PR1, PR3, PR5, and PR6, and IN1, IN2, and IN3, respectively.

One main result of these tests is the very strong link between injury profiles and patterns of cropping practices $\left(\chi^{2}=573, P\right.$ $<0.0005)$. Significant associations between yield classes and patterns of cropping practices $\left(\chi^{2}=102, P<0.0005\right)$, and between yield classes and injury profiles $\left(\chi^{2}=59.6, P<0.0005\right)$ were also found. There were also very strong associations between weather patterns and patterns of cropping practices, as well as between weather patterns and injury profiles $\left(\chi^{2}>\right.$ $500, P<0.0005$ in both cases).

Linkage of actual yields with yieldlimiting and yield-reducing factors. Analyzing this survey yielded information on a large number of relationships among paired variables that were examined in their corresponding contingency tables. A few of these relationships, all involving variation in actual yield levels (Y1 to Y5), are summarized in Table 7. Most of the relationships between $\mathrm{Y}$ and components of cropping practices (whose variations may be seen as varying levels of yieldlimiting factors) or injuries (which may be seen as yield-reducing factors) are significant, but are complex and nonlinear. Some of the relationships listed in Table 7 are straightforward, such as the yield-limiting effect of DS and WE and the yield-reducing effects of SHR, BS, NB, WA, and WB. Other relationships must be cautiously interpreted. One example is the significant and positive link between pesticide use (IU, HU, and FU) and Y. Another type of complex, pair-wise relationship is between yield-limiting (cropping practices) and yield-reducing (injuries) variables. For instance, there is a significant relationship between the crop establishment method (PM) and sheath blight level (SHB): $\chi^{2}=$ $37.8, \mathrm{df}=2, P<0.0005$. The contingency table associated with this test (not shown) indicates that high SHB incidence (percent tillers infected) is observed significantly more frequently in transplanted than in

Table 4. Weather variables pertaining to sites and seasons considered in the survey

\begin{tabular}{|c|c|c|c|c|c|c|c|c|c|}
\hline \multirow[b]{2}{*}{ Site $^{a}$} & \multirow[b]{2}{*}{ Cropping season } & \multicolumn{2}{|c|}{$\mathbf{T X}^{\mathbf{b}}$} & \multicolumn{2}{|c|}{$\mathbf{T N}^{\mathbf{b}}$} & \multicolumn{2}{|c|}{$\mathbf{R A D}^{\mathbf{b}}$} & \multicolumn{2}{|c|}{ RAIN $^{b}$} \\
\hline & & Meanc & SD $^{d}$ & Meanc $^{\mathrm{c}}$ & SD $^{d}$ & Meanc & SD $^{\mathbf{d}}$ & Total $^{\mathrm{e}}$ & SD $^{\mathbf{d}}$ \\
\hline CLUZ & Rainy season 1987 & 32.3 & 3 & 24.6 & 0.8 & 22.4 & 5.5 & 777 & 14.6 \\
\hline CLUZ & Dry season 1987 & 31.8 & 1.4 & 22.4 & 1.4 & 23.7 & 3.5 & 39 & 2.6 \\
\hline FAIZ & Rainy season 1992 & 32.5 & 1.7 & 23.3 & 3.1 & 17.8 & 3.9 & 672 & 20.9 \\
\hline FAIZ & Rainy season 1993 & 32.1 & 2.2 & 23.7 & 4.1 & 15.8 & 3.6 & 306 & 8.1 \\
\hline HGZ & Early spring 1997 & 30.8 & 3.9 & 20.2 & 3.8 & 15.1 & 6.6 & 613 & 18.0 \\
\hline ILO & Rainy season 1996 & 31.1 & 1.3 & 22.6 & 0.9 & 18.8 & 4.2 & 854 & 20.1 \\
\hline LAG & Dry season 1996 & 28.8 & 2.0 & 21.9 & 1.4 & 15.6 & 4.5 & 76 & 2.3 \\
\hline LAG & Rainy season 1996 & 31.7 & 1.4 & 23.5 & 0.8 & 16.0 & 4.4 & 850 & 17.4 \\
\hline $\mathrm{MD}$ & Winter season 1996 & 30.0 & 1.7 & 22.6 & 1.4 & 18.0 & 4.3 & 26 & 1.3 \\
\hline MD & Dry season 1996 & 32.5 & 1.4 & 25.1 & 0.9 & 19.6 & 3.8 & 503 & 14.3 \\
\hline MD & Rainy season 1996 & 31.2 & 1.5 & 24.4 & 1.0 & 17.7 & 4.0 & 864 & 16.3 \\
\hline
\end{tabular}

a CLUZ: Central Luzon; FAIZ: Faizabad; HGZ: Hangzhou; ILO: Ilo-Ilo; LAG: Laguna; MD: Mekong Delta.

b See Table 1 for list of variables.

${ }^{c}$ Mean daily value over the average crop cycle duration in the corresponding season and site.

d Standard deviation about the mean daily value over the average crop cycle duration in the corresponding season and site.

e Accumulated total rainfall during the average crop cycle duration in the corresponding season and site. 

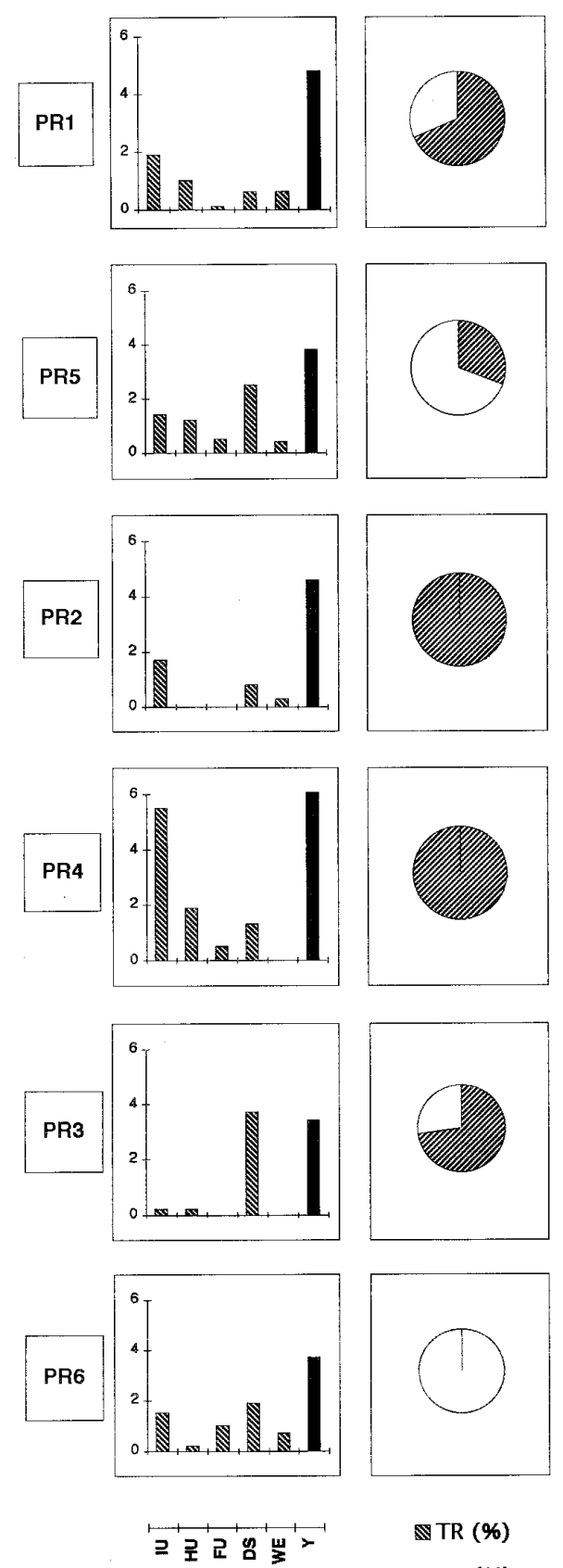
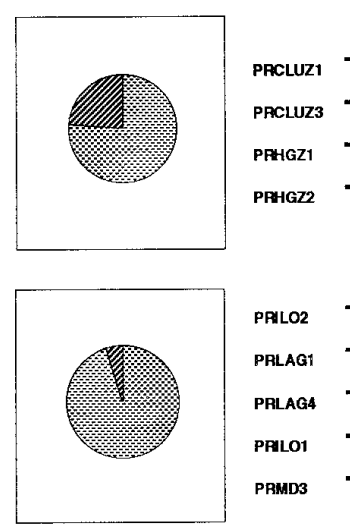

PRILO2

PRLAG1

PRLAG4

PFLO1

PRMD3

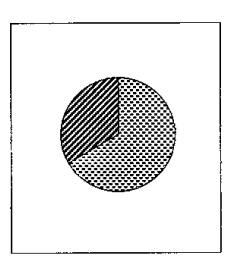

PACluz5

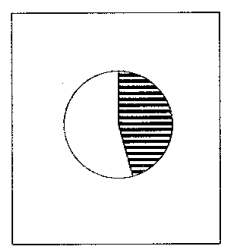

PRAGG3

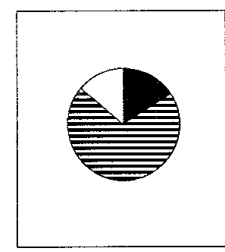

PRFAZ1

PRFAIZ15

PRFAZ3

PRFAlZ11

PRFAZ2

PRALO3

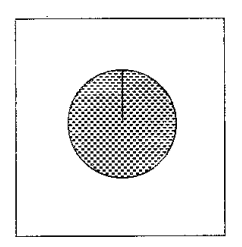

PRMD5

PRMDA

图 Rice (\%)

Fallow (\%)

c Legume (\%)

E Cereal (\%)

$\square$ Misc. (\%)

Chi-square distance
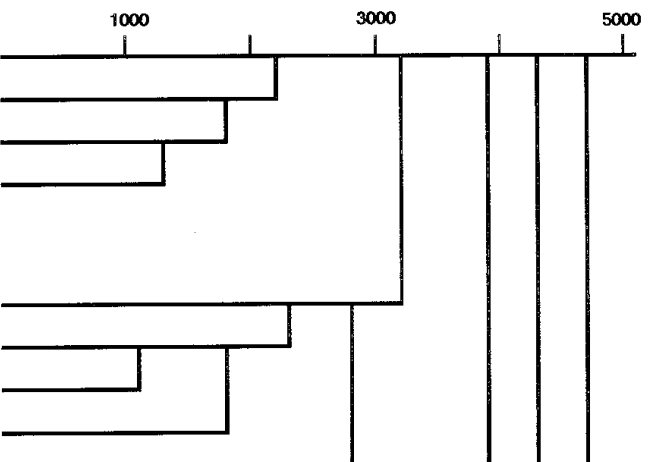

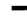
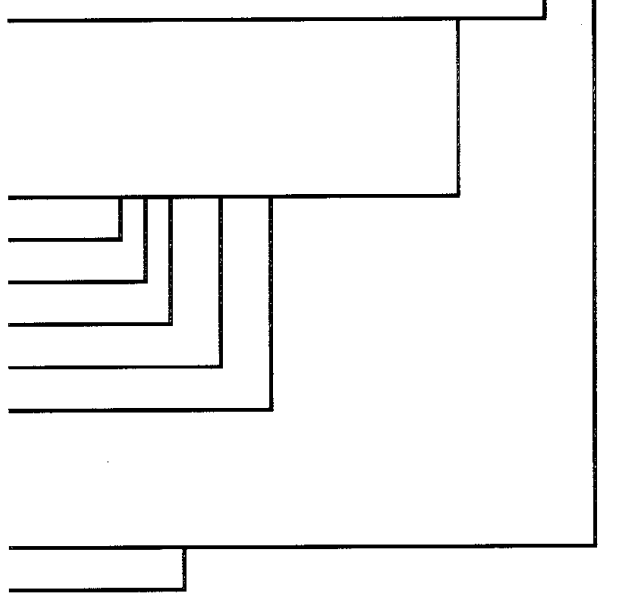

Fig. 2. Cluster analysis of components of cropping practices using a nearest neighbor method and a chi-square distance in six sites in tropical Asia. Six production situations (PR) are characterized. The analysis involves 10 categorized variables (Table 2). Some of the main cluster (PR) attributes are indicated on the left: insecticide use (IU, mean number of applications per cropping season), herbicide use (HU, mean number of applications), fungicide use (FU, mean number of applications), drought stress (DS, mean rating), water excess (WE, mean rating), crop establishment method (direct seeding, DS, or transplanting, TR; the sectors represent proportion of fields established in each PR), and crop preceding the rice crops (rice, fallow, legume, cereal, or miscellaneous crops, sectors represent fraction of preceding crops in each PR). Mean yields (Y) in each PR are indicated by solid bars. Y was not involved in the analysis. Within-site clusters (labeled PR SITE no., e.g., PRCLUZ1) generated from preliminary cluster analyses (not shown) using the same procedure are indicated. 
direct-seeded fields, although the prevalence (percent fields affected) of the disease is the same in both types of crop establishment.

Simple correspondence analyses. Three contingency tables, $[\mathrm{IN} \times \mathrm{PR}],[\mathrm{PR}$ $\times \mathrm{Y}]$, and $[\mathrm{IN} \times \mathrm{Y}]$, were submitted separately to correspondence analyses. In all three cases, only clusters with more than 30 individuals ( $n \geq 30$ fields) were involved as active (axis-determining) variables (i.e., PR1, PR3, PR5, and PR6; and IN1, IN2, and IN3), while the other clusters were included as additional variables in the analyses. In all three analyses, the two first axes accounted for accumulated inertia larger than $75 \%$. Figure 5 shows the graphic outputs of these analyses.

Figure 5A $([\mathrm{IN} \times \mathrm{PR}])$ shows that PR1, PR2, and PR4 are closely linked to IN1, while PR3 is associated with IN3 and IN5, and PR5 and PR6 are associated with IN2. Thus, patterns of cropping practices and injury profiles are closely related, regardless of the site. In the second analysis, a path of increasing levels has been drawn for the ordinal (categorized) variable, $\mathrm{Y}$ (Fig. 5B, $[\mathrm{PR} \times \mathrm{Y}]$ ). This path is mostly accounted for by the first (horizontal) axis and progresses from patterns of cropping practices PR3 and PR5 to PR1, and toward PR4. PR6 and PR2 are comparatively away from this path, the former being more associated with low yields, and the latter with high yields. This analysis illustrates the strong link between patterns of cropping practices and Y. The description of the same yield levels involves the two first axes when injuries are considered (Fig. $5 \mathrm{C},[\mathrm{IN} \times \mathrm{Y}])$. This third graph indi- cates that, although a good description of yield variation (a clearly delineated path) can be achieved when injury profiles are considered, no specific injury profile appears to be strongly directly associated with a given yield level.

Correspondence analysis among clusters. The array of relationships portrayed in Figure 5A, B, and C can be addressed in a single Burt table, which is similar in construction to a correlation matrix, except that each correlation is represented by a contingency table. Additional information pertaining to the sites, the weather types, and the yield levels was appended to the Burt table. The numerical outputs of the correspondence analysis are shown in Table 8. The main features of this analysis can be summarized as follows.

Table 5. Characteristics of patterns of cropping practices generated from cluster analyses across six sites in tropical Asia

\begin{tabular}{|c|c|c|c|c|c|c|c|}
\hline & & \multicolumn{6}{|c|}{ Clusters of cropping practices across sites ${ }^{a}$} \\
\hline & & PR1 $^{b, c}(148)$ & $\mathbf{P R 2}^{\mathrm{b}, \mathrm{d}}(\mathbf{6})$ & $\operatorname{PR3}^{\mathrm{b}, \mathrm{e}}(140)$ & $\mathbf{P R 4}^{\text {b,f }}(\mathbf{1 1})$ & $\mathbf{P R 5}^{\mathrm{b}, \mathrm{g}}(\mathbf{8 1})$ & PR6 $^{\text {b,h }}(33)$ \\
\hline \multirow[t]{3}{*}{$M^{i, j}$} & $\mathrm{Y}_{\mathrm{MF}}$ & 137 & 100 & 98 & 260 & 133 & 159 \\
\hline & $\mathrm{M}_{\mathrm{MF}}$ & 150 & 100 & 100 & 272 & 129 & 162 \\
\hline & $\mathrm{SEM}_{\mathrm{MF}}$ & 6 & 11 & 4 & 12 & 6.5 & 11 \\
\hline \multirow[t]{3}{*}{$\mathrm{FP}^{\mathrm{i}}$} & $\mathrm{Y}_{\mathrm{FP}}$ & 137 & 160 & 78 & 3 & 53 & 9 \\
\hline & $\mathrm{M}_{\mathrm{FP}}$ & 112 & 120 & 90 & 3 & 60 & 11 \\
\hline & $\mathrm{SEM}_{\mathrm{FP}}$ & 6 & 36 & 2 & 3 & 5 & 1 \\
\hline \multirow[t]{3}{*}{ WCPi,k } & Hand & 37.2 & 0 & 89.3 & 54.5 & 34.6 & 0 \\
\hline & Herb & 60.8 & 0 & 10.7 & 45.5 & 61.7 & 3 \\
\hline & NW & 2 & 100 & 0 & 0 & 3.7 & 97 \\
\hline \multirow[t]{3}{*}{$\mathrm{IU}^{\mathrm{i}}$} & $\mathrm{Y}_{\mathrm{IU}}$ & 1.9 & 1.7 & 0.2 & 5.5 & 1.4 & 1.5 \\
\hline & $\mathrm{M}_{\mathrm{IU}}$ & 2 & 2 & 0 & 6 & 1 & 1 \\
\hline & $\mathrm{SEM}_{\mathrm{IU}}$ & 0.1 & 0.4 & 0 & 0 & 0.1 & 0.2 \\
\hline \multirow[t]{3}{*}{$\mathrm{HU}^{\mathrm{i}}$} & $\mathrm{Y}_{\mathrm{HU}}$ & 1 & 0 & 0.2 & 1.9 & 1.2 & 0.2 \\
\hline & $\mathrm{M}_{\mathrm{HU}}$ & 1 & 0 & 0 & 2 & 1 & 0 \\
\hline & $\mathrm{SEM}_{\mathrm{HU}}$ & 0 & 0 & 0 & 0 & 0.1 & 0.1 \\
\hline \multirow[t]{3}{*}{$\mathrm{FU}^{\mathrm{i}}$} & $\mathrm{Y}_{\mathrm{FU}}$ & 0.1 & 0 & 0 & 0.5 & 0.5 & 1 \\
\hline & $\mathrm{M}_{\mathrm{FU}}$ & 0 & 0 & 0 & 0 & 0 & 1 \\
\hline & $\mathrm{SEM}_{\mathrm{FU}}$ & 0 & 0 & 0 & 0 & 0.1 & 0.2 \\
\hline \multirow[t]{3}{*}{$\mathrm{DS}^{\mathrm{i}}$} & $\mathrm{Y}_{\mathrm{DS}}$ & 0.6 & 0.8 & 3.7 & 1.3 & 2.5 & 1.9 \\
\hline & $\mathrm{M}_{\mathrm{DS}}$ & 0 & 0.5 & 4 & 1 & 3 & 2 \\
\hline & $\mathrm{SEM}_{\mathrm{DS}}$ & 0.1 & 0.4 & 0 & 0.3 & 0.1 & 0.2 \\
\hline \multirow[t]{3}{*}{$\mathrm{WE}^{\mathrm{i}}$} & $\mathrm{Y}_{\mathrm{WE}}$ & 0 & 0.3 & 0 & 0 & 0.4 & 0.7 \\
\hline & $\mathrm{M}_{\mathrm{WE}}$ & 0 & 0 & 0 & 0 & 0 & 0 \\
\hline & $\mathrm{SEM}_{\mathrm{WE}}$ & 0 & 0.2 & 0 & 0 & 0.1 & 0.2 \\
\hline \multirow[t]{2}{*}{$\mathrm{PM}^{\mathrm{i}, 1}$} & $\mathrm{TR}$ & 68.2 & 100 & 72.9 & 100 & 30.9 & 0 \\
\hline & DS & 31.8 & 0 & 27.1 & 0 & 69.1 & 100 \\
\hline \multirow[t]{5}{*}{$\mathrm{PC}^{\mathrm{i}, \mathrm{m}}$} & Rice & 76.4 & 66.7 & 0 & 0 & 95.1 & 100 \\
\hline & Fal & 23.6 & 33.3 & 0 & 0 & 4.9 & 0 \\
\hline & Leg & 0 & 0 & 15.7 & 0 & 0 & 0 \\
\hline & $\mathrm{W} / \mathrm{B}$ & 0 & 0 & 70.7 & 45.5 & 0 & 0 \\
\hline & Misc & 0 & 0 & 13.6 & 54.5 & 0 & 0 \\
\hline \multirow[t]{3}{*}{$Y^{i, n}$} & $\mathrm{Y}_{\mathrm{Y}}$ & 4.8 & 4.6 & 3.5 & 6.7 & 3.8 & 3.9 \\
\hline & $\mathrm{M}_{\mathrm{Y}}$ & 4.8 & 4.6 & 3.4 & 6.7 & 3.6 & 3.7 \\
\hline & SEM $_{Y}$ & 0.1 & 0.2 & 0.1 & 0.3 & 0.1 & 0.3 \\
\hline
\end{tabular}

a Names of between-site clusters are followed by the total number of fields belonging to the clusters.

b CLUZ: Central Luzon; FAIZ: Faizabad; HGZ: Hangzhou; ILO: Ilo-Ilo; LAG: Laguna; MD: Mekong Delta.

c PR1 includes the within-site clusters PRCLUZ1, PRCLUZ3, PRHGZ1, and PRHGZ2, having 87, 39, 14, and 8 fields, respectively.

${ }^{d}$ PR2 includes the within-site cluster PRCLUZ5, having 6 fields.

e PR3 includes the within-site clusters PRFAIZ1, PRFAIZ2, PRFAIZ3, PRFAIZ11, PRFAIZ15, and PRILO3, having 79, 8, 12, 21, 5, and 15 fields, respectively.

${ }^{\mathrm{f}}$ PR4 includes the within-site cluster PRHZ3, having 11 fields.

g PR5 includes the within-site clusters PRILO1, PRILO2, PRLAG1, PRLAG4, and PRMD4, having 14, 7, 18, 7, and 35 fields, respectively.

${ }^{\text {h }}$ PR6 includes the within-site clusters PRMD4 and PRMD5, having 23 and 10 fields, respectively.

i See Table 1 for list of variables.

j $\mathrm{Y}=$ mean, $\mathrm{M}=$ median, $\mathrm{SEM}=$ standard error of the mean.

${ }^{\mathrm{k}}$ Percent fields with Hand = some hand weeding; Herb = exclusive reliance on herbicides for weed control; NW = no direct weed control measure.

${ }^{\mathrm{I}} \mathrm{TR}=$ percent transplanted; DS = percent direct-seeded fields in the cluster.

mPercent fields with: Rice: rice; Fal: fallow; Leg: legume; W/B: wheat or barley; Misc: miscellaneous crops, preceding the surveyed rice crop.

${ }^{\mathrm{n}}$ Yield estimates were not included in the clustering. 
The two first axes that were generated accounted for an accumulated inertia of $85.3 \%$. PR3 and IN3 are strongly associated along, and are major defining variables of, axis 1. PR1, PR5, and PR6, and IN1 and IN2 are the main variables defining the second axis. On this axis, PR 1 and IN1 are associated and opposed to PR5, PR6, and IN2 in another group of variables. These two first axes account very well for variations in PR and IN across most sites. Each site described with these two sets of (synthetic) variables is therefore well described in this analysis (the poorest description is that of ILO, with an accumulated inertia accounted for of only $7.77 \%$, followed by LAG at $67.5 \%$, up to FAIZ at nearly $100 \%$ ). The two first axes also provide a very good description of all yield levels (from 82.6\%: Y2 to 95.0\%: Y4) except Y3 $(2.37 \%)$ - the midrange of yield levels-which is very close to the origin of axes and therefore cannot have a large inertia. Coordinates of yield classes on both axes indicate strong yield gradients. The reciprocal contributions of weather patterns accumulated on both axes range from 87.4 to $99.8 \%$. Thus, the analy- sis yields an excellent representation of weather patterns.

The graphic output of the analysis is shown in Figure 6. Three groups of variables are distinguished: (i) a first group, centered around PR3 and including IN3 and IN4, which is associated with W3 and corresponds to FAIZ; (ii) a second group, centered around PR1 and including PR2, PR4, and IN1, which is associated with W2 and corresponds to CLUZ and HGZ; and (iii) a third group, involving PR5 and PR6 and including IN2. This group is associated with W5 and W6 and corresponds
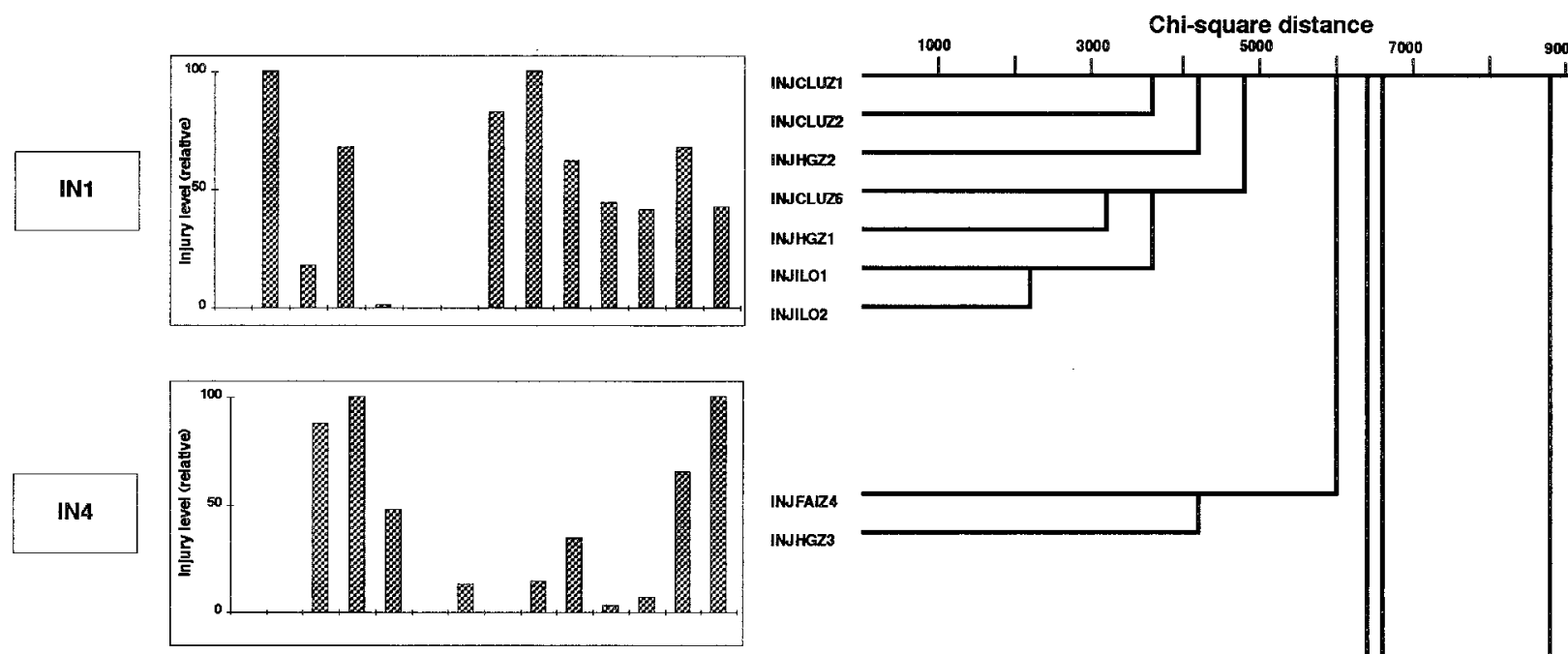

INJFAIZ4

INUHGZ3
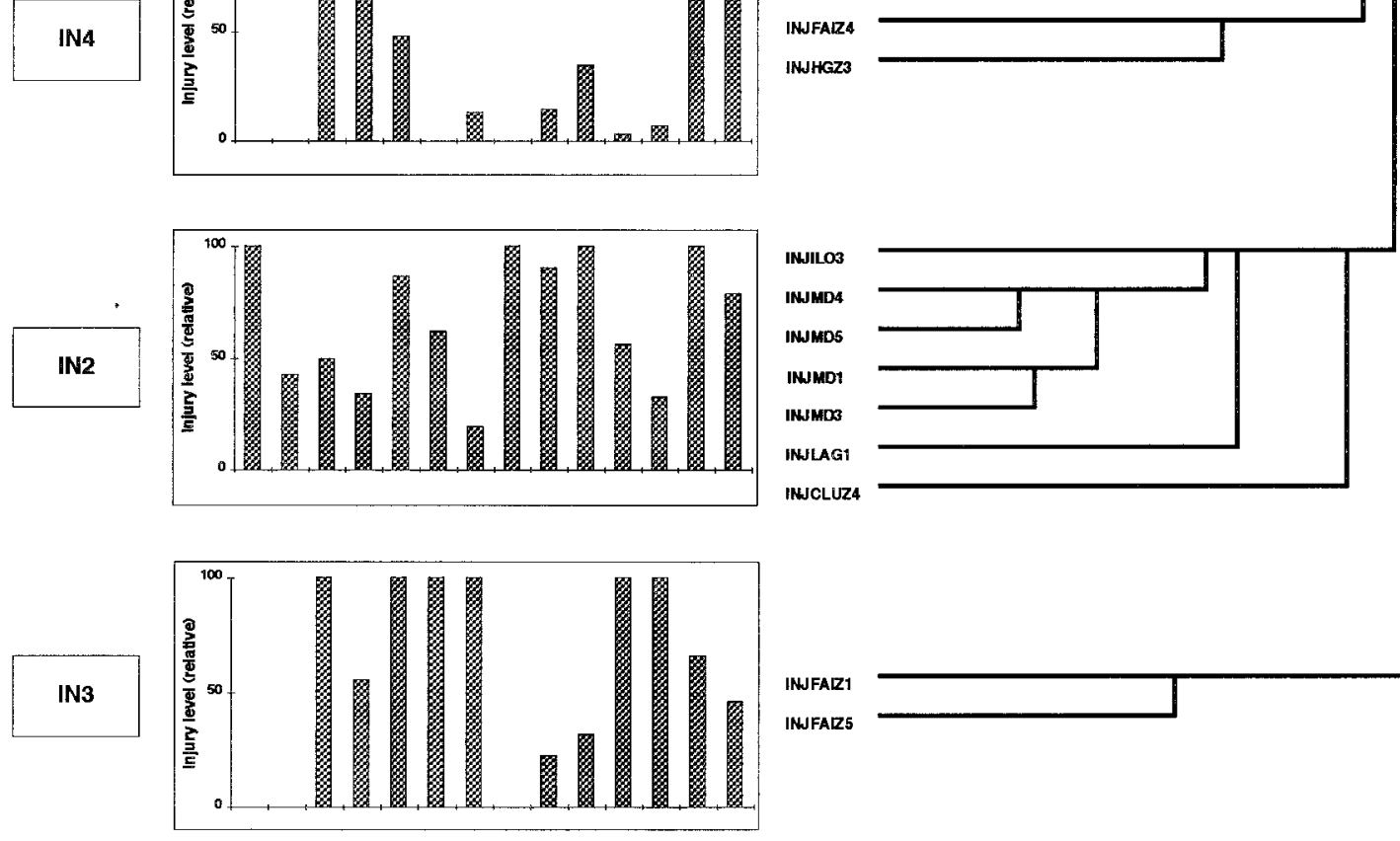

INJFAZ1

INWFAZS

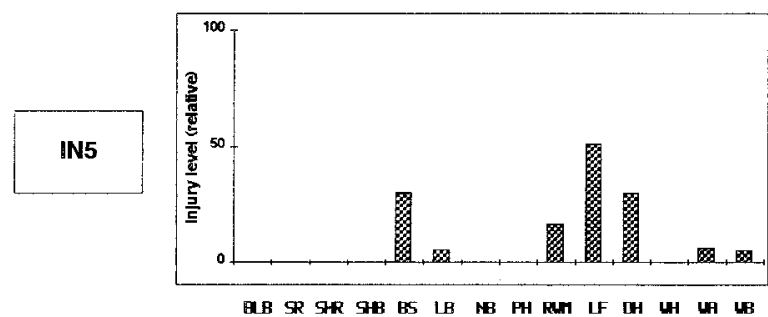

INJFAZZ

Fig. 3. Cluster analysis of injuries using a nearest neighbor method and a chi-square distance in six sites in tropical Asia. Five production situations (IN) are characterized. The analysis involves 14 categorized variables (Table 2). Characteristics of injury profiles are outlined on the left (vertical bars represent injury levels made relative to the highest within-cluster mean level): BLB: bacterial leaf blight; SR: stem rot; SHR: sheath rot; SHB: sheath blight; BS: brown spot; LB: leaf blight; NB: neck blight; PH: plant hoppers; RWM: rice whorl maggot; LF: leaf folder; DH: dead hearts; WH: white heads; WA: weed infestation above the crop canopy; and WB: weed infestation below the crop canopy. Within-site injury clusters (labeled INJ SITE no., e.g., INJCLUZ1) generated from preliminary cluster analyses (not shown) using the same procedure are indicated. 
to $\mathrm{LAG}$ and MD. A path of increasing yield levels has been outlined in Figure 6 and indicates a regular increase from PR3 and IN3 (the first group, associated with FAIZ and weather type W3) to PR1 and IN1 (the second group, corresponding to CLUZ and HGZ, with weather type W2). This path of yield increase also takes the direction of $\mathrm{W} 1$ and $\mathrm{W} 4$. The location of PR5, PR6, and IN2 (the third group) rela- tive to the path of increasing yield levels indicates that this group is associated with a range of yields, from low to high.

\section{DISCUSSION}

Some of the injuries listed in Table 3 appear near-omnipresent (SHR, SHB, BS, $\mathrm{PH}, \mathrm{RWM}, \mathrm{LF}, \mathrm{DH}, \mathrm{WH}$, and particularly, WA and WB), while others are not (BLB, $\mathrm{SR}, \mathrm{LB}, \mathrm{NB})$. Rice tungro disease and rat

Table 6. Characteristics of injury profiles of rice crops generated from cluster analyses across six sites in tropical Asia

\begin{tabular}{|c|c|c|c|c|c|c|}
\hline & & \multicolumn{5}{|c|}{ Clusters of injury profiles across sites ${ }^{\mathrm{a}}$} \\
\hline & & IN1 $1^{b, c}(180)$ & $\mathrm{IN} 2^{\mathrm{b}, \mathrm{d}}(\mathbf{1 0 8})$ & $\mathrm{IN}^{\mathrm{b}, \mathrm{e}}(\mathbf{1 2 3})$ & IN4 $4^{b, f}(14)$ & IN5 $5^{b, g}(4)$ \\
\hline \multirow[t]{3}{*}{$\mathrm{BLB}^{\mathrm{h}, \mathrm{i}}$} & $\mathrm{Y}_{\mathrm{BLB}}$ & 0 & 75 & 0 & 0 & 0 \\
\hline & $\mathrm{M}_{\mathrm{BLB}}$ & 0 & 0 & 0 & 0 & 0 \\
\hline & $\mathrm{SEM}_{\mathrm{BLB}}$ & 0 & 22 & 0 & 0 & 0 \\
\hline \multirow[t]{3}{*}{$\mathrm{SR}^{\mathrm{h}}$} & $\mathrm{Y}_{\mathrm{SR}}$ & 8.5 & 3.6 & 0 & 0 & 0 \\
\hline & $\mathrm{M}_{\mathrm{SR}}$ & 0 & 0 & 0 & 0 & 0 \\
\hline & $\mathrm{SEM}_{\mathrm{SR}}$ & 1.4 & 1 & 0 & 0 & 0 \\
\hline \multirow[t]{3}{*}{$\mathrm{SHR}^{\mathrm{h}}$} & $\mathrm{Y}_{\mathrm{SHR}}$ & 1.3 & 3.6 & 7.3 & 6.4 & 0 \\
\hline & $\mathrm{M}_{\mathrm{SHR}}$ & 0 & 0.6 & 7.5 & 3.5 & 0 \\
\hline & $\mathrm{SEM}_{\mathrm{SHR}}$ & 0.2 & 0.8 & 0.5 & 2.4 & 0 \\
\hline \multirow[t]{3}{*}{$\mathrm{SHB}^{\mathrm{h}}$} & $\mathrm{Y}_{\mathrm{SHB}}$ & 12.1 & 6.1 & 9.9 & 17.9 & 0 \\
\hline & $\mathrm{M}_{\mathrm{SHB}}$ & 4.2 & 2.7 & 8.6 & 11.4 & 0 \\
\hline & $\mathrm{SEM}_{\mathrm{SHB}}$ & 1.3 & 0.8 & 0.9 & 4.7 & 0 \\
\hline \multirow[t]{3}{*}{$\mathrm{BS}^{\mathrm{h}}$} & $\mathrm{Y}_{\mathrm{BS}}$ & 7 & 628 & 727 & 345 & 216 \\
\hline & $\mathrm{M}_{\mathrm{BS}}$ & 0 & 28 & 679 & 207 & 144 \\
\hline & $\mathrm{SEM}_{\mathrm{BS}}$ & 2 & 89 & 43 & 109 & 64 \\
\hline \multirow{3}{*}{$\mathrm{LB}^{\mathrm{h}}$} & $\mathrm{Y}_{\mathrm{LB}}$ & 0 & 49 & 79 & 0 & 4 \\
\hline & $\mathrm{M}_{\mathrm{LB}}$ & 0 & 0 & 0 & 0 & 0 \\
\hline & $\mathrm{SEM}_{\mathrm{LB}}$ & 0 & 15 & 26 & 0 & 4 \\
\hline \multirow{3}{*}{$\mathrm{NB}^{\mathrm{h}}$} & $\mathrm{Y}_{\mathrm{NB}}$ & 0 & 0.9 & 4.7 & 0.6 & 0 \\
\hline & $\mathrm{M}_{\mathrm{NB}}$ & 0 & 0 & 0 & 0 & 0 \\
\hline & $\mathrm{SEM}_{\mathrm{NB}}$ & 0 & 0.3 & 0.9 & 0.4 & 0 \\
\hline \multirow[t]{3}{*}{$\mathrm{PH}^{\mathrm{h}}$} & $\mathrm{Y}_{\mathrm{PH}}$ & 33 & 40 & 0 & 0 & 0 \\
\hline & $\mathrm{M}_{\mathrm{PH}}$ & 14 & 19 & 0 & 0 & 0 \\
\hline & $\mathrm{SEM}_{\mathrm{PH}}$ & 4 & 5 & 0 & 0 & 0 \\
\hline \multirow{3}{*}{$\mathrm{RWM}^{\mathrm{h}}$} & $\mathrm{Y}_{\mathrm{WM}}$ & 161 & 145 & 36 & 23 & 26 \\
\hline & $\mathrm{M}_{\mathrm{WM}}$ & 50 & 50 & 28 & 17 & 44 \\
\hline & $\mathrm{SEM}_{\mathrm{WM}}$ & 17 & 22 & 3 & 7 & 12 \\
\hline \multirow[t]{3}{*}{$\mathrm{LF}^{\mathrm{h}}$} & $Y_{L F}$ & 124 & 200 & 63 & 69 & 101 \\
\hline & $\mathrm{M}_{\mathrm{LF}}$ & 43 & 83 & 55 & 60 & 84 \\
\hline & $\mathrm{SEM}_{\mathrm{LF}}$ & 19 & 30 & 4 & 14 & 17 \\
\hline \multirow[t]{3}{*}{$\mathrm{DH}^{\mathrm{h}}$} & $\mathrm{Y}_{\mathrm{DH}}$ & 1.5 & 1.9 & 3.4 & 0.1 & 1 \\
\hline & $\mathrm{M}_{\mathrm{DH}}$ & 0.2 & 0.8 & 3.1 & 0 & 0 \\
\hline & $\mathrm{SEM}_{\mathrm{DH}}$ & 0.2 & 0.2 & 0.3 & 0.1 & 1 \\
\hline \multirow[t]{3}{*}{$\mathrm{WH}^{\mathrm{h}}$} & $\mathrm{Y}_{\mathrm{WH}}$ & 2.4 & 1.9 & 5.8 & 0.4 & 0 \\
\hline & $\mathrm{M}_{\mathrm{WH}}$ & 0.8 & 0 & 5.9 & 0 & 0 \\
\hline & $\mathrm{SEM}_{\mathrm{WH}}$ & 0.3 & 0.4 & 0.2 & 0.1 & 0 \\
\hline \multirow[t]{3}{*}{$\mathrm{WA}^{\mathrm{h}}$} & $\mathrm{Y}_{\mathrm{WA}}$ & 291 & 429 & 282 & 280 & 25 \\
\hline & $\mathrm{M}_{\mathrm{WA}}$ & 103 & 250 & 175 & 138 & 33 \\
\hline & $\mathrm{SEM}_{\mathrm{WA}}$ & 44 & 51 & 32 & 108 & 11 \\
\hline \multirow[t]{3}{*}{$\mathrm{WB}^{\mathrm{h}}$} & $\mathrm{Y}_{\mathrm{WB}}$ & 300 & 557 & 325 & 707 & 33 \\
\hline & $\mathrm{M}_{\mathrm{WB}}$ & 100 & 256 & 242 & 275 & 33 \\
\hline & $\mathrm{SEM}_{\mathrm{WB}}$ & 40 & 70 & 33 & 244 & 24 \\
\hline \multirow[t]{3}{*}{$Y^{h, j}$} & $\mathrm{Y}_{\mathrm{Y}}$ & 4.6 & 3.9 & 3.5 & 4.3 & 3.3 \\
\hline & $\mathrm{M}_{\mathrm{Y}}$ & 4.7 & 3.7 & 3.4 & 4 & 3.1 \\
\hline & $\mathrm{SEM}_{\mathrm{Y}}$ & 0.1 & 0.1 & 0.1 & 0.4 & 0.3 \\
\hline
\end{tabular}

a Names of between-site clusters are followed by the total number of fields belonging to the clusters.

b CLUZ: Central Luzon; FAIZ: Faizabad; HGZ: Hangzhou; ILO: Ilo-Ilo; LAG: Laguna; MD: Mekong Delta.

${ }^{c}$ IN1 includes the within-site clusters INJCLUZ1, INJCLUZ2, INJCLUZ6, INJILO1, INJILO2, INJHGZ1, and INJHGZ2, having 113, 7, 6, 9, 19, 18, and 8 fields, respectively.

d IN2 includes the within-site clusters INJCLUZ4, INJILO5, INJLAG1, INJMD1, INJMD2, INJMD3, and INJMD4, having 6, 7, 24, 22, 10, 18, and 21 fields, respectively.

${ }^{\mathrm{e}}$ IN3 includes the within-site clusters INJFAIZ1 and INJFAIZ5, which have 98 and 25 fields, respectively.

${ }^{\mathrm{f}}$ IN4 includes the within-site clusters INJFAIZ4 and INJHGZ3, which have 10 and 4 fields, respectively.

g IN5 includes the within-site cluster INJFAIZ8, which has 4 fields.

${ }^{\mathrm{h}}$ See Table 1 for list of variables.

i $\mathrm{Y}=$ mean, $\mathrm{M}=$ median, $\mathrm{SEM}=$ standard error of the mean.

j Yield estimates were not included in the clustering. injuries, which were included in the survey procedure at all sites, were not considered in the analyses because of their low prevalence and their site-specificity. One striking result of this study is the comparatively low prevalence of the most commonly cited and studied rice disease: leaf blast. This leads to two interpretations: (i) the currently deployed rice varieties exhibit a sufficient level of resistance to the disease, and (ii) this disease heavily depends on climatic conditions to develop strong epidemics, which were not encountered in all sites or seasons covered by the analysis. The survey indeed covered environments where strong blast epidemics should be expected (35), but they did not occur, primarily because of the regular release and deployment of resistant varieties. Similar reasoning could be applied to several other injuries, such as BLB, NB (both with a wide range of prevalences, Table 3 ), or even $\mathrm{PH}$ (which exhibits generally high prevalences).

That a particular injury prevails in nearly all sites or season is not necessarily an indication of its importance. By contrast, some injuries may occur sporadically and cause considerable yield reductions. Rice tungro disease exemplifies this type of injury (4). A combination of information on occurrences of injuries and on experimental measurement of yield losses they may cause is necessary to assess the importance of a given injury. This paper deals with the first category of information only, i.e., the occurrence of injuries and their agroecological context.

While six clusters of cropping practices were identified, only four (PR1, PR3, PR5, and PR6) accounted for the large majority of fields and were further involved in the analysis as active variables. PR1 is the most common pattern and is shared by two sites (Fig. 4B). It consists essentially of fields in a rice-rice rotation, with relatively high input, relatively long fallow periods, and transplanted crops. PR3 typifies fields of the rice-wheat system of southern Asia, with their diversity of rotations and low inputs (except in the form of labor). Interestingly, this pattern is also found in ILO (Philippines), presumably because of the similarities in rotations and low (chemical) inputs. PR5 is not represented by a large population of fields, but it is shared by three very different sites (ILO, LAG, and MD). Many of these fields are direct seeded (often at very high rates), with relatively low fertilizer input, often in a rice monoculture. PR6, which is found in MD only, typifies the very intensive rice production systems of Southeast Asiaand concerns agronomists $(10,13)$ and plant pathologists $(5,8)$ with respect to its sustainability. Rice fields in this pattern are part of an intense rice monoculture with high (chemical) input. The main result achieved at this step of the analysis is that a few patterns of cropping practices were 


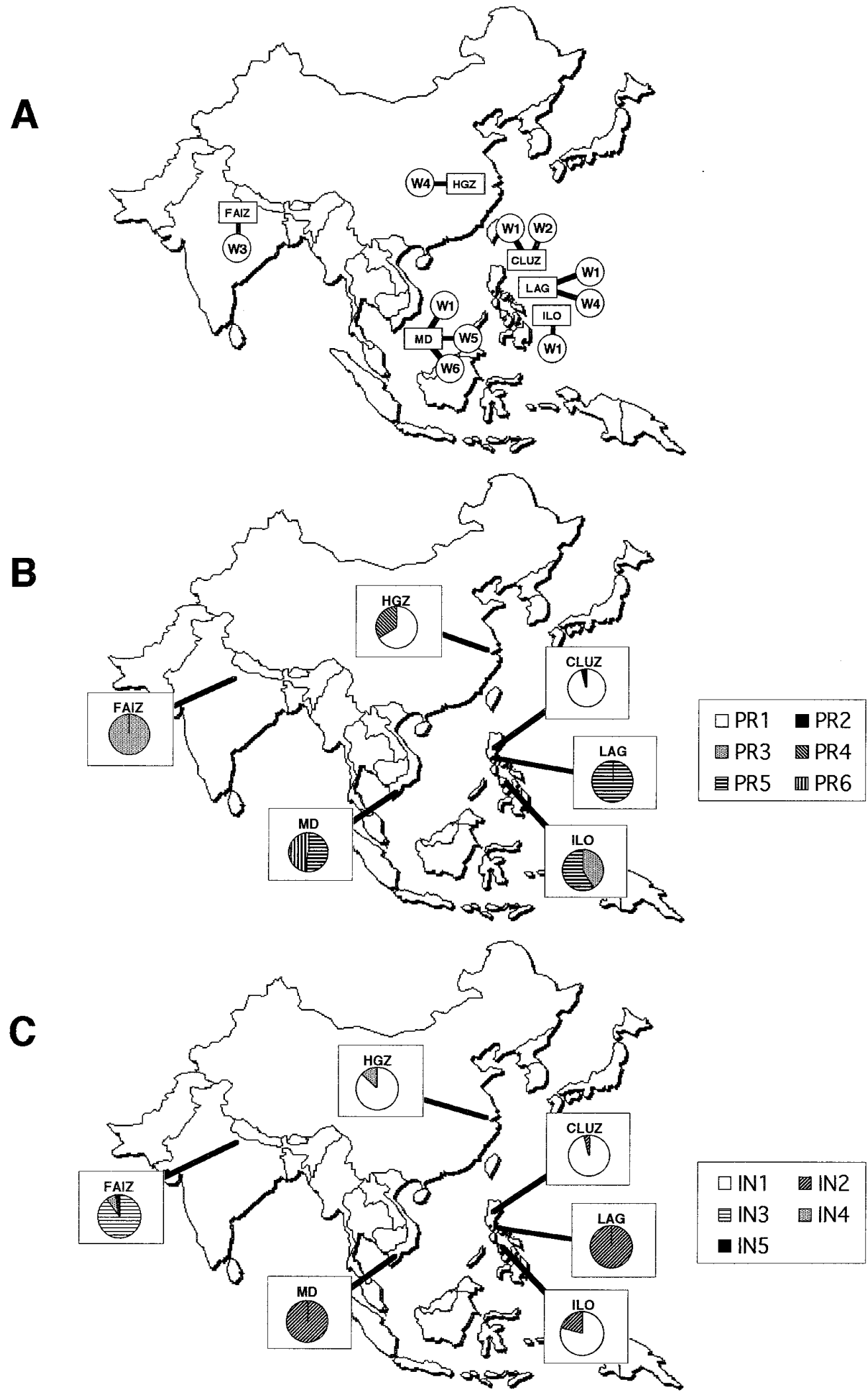

Fig. 4. Geographic display of (A) patterns of weather (W, Fig. 1) in six sites, (B) patterns of cropping practices (PR, Fig. 2), and (C) injury profiles (IN, Fig. 3) generated from cluster analyses. Each site may be associated with different weather patterns (A) corresponding to different cropping seasons in a year. Sectors indicate proportions of fields in a site with a given pattern of cropping practice (B) or injury profile (C). 
identified, among which some are common across sites and seasons.

Of the five clusters of injuries found, three (IN1, IN2, and IN3) accounted for most of the fields surveyed. IN1 is an injury profile where tiller injuries (SHB and SR) predominate, along with $\mathrm{PH}$ and RWM. This profile is common to three very distant sites: HGZ, CLUZ, and ILO (Fig. 4C). IN2 is characterized by the occurrence of BLB and comparatively high levels of BS, LB, RWM, and LF. Weed infestation is also the highest in IN2. This profile is found in four sites (CLUZ, LAG, ILO, and MD) and appears characteristic of the warm, humid tropics of Southeast Asia. Injury profile IN3 is associated with high levels of SHR, NB, DH, and WH, in addition to some of the injuries found in IN2 (BS, LB) or both IN1 and IN2 (RWM). By contrast with the two first profiles, this third one is found in only one site (FAIZ), where it predominates. High $\mathrm{BS}, \mathrm{DH}$, and SHR (the latter two being frequently associated injuries) indeed are typical of the biotic constraints of rice in the rice-wheat system of southern Asia (20). It is worth noting that a fourth profile (IN4) was found to be shared by two very distant sites (FAIZ and HGZ), where cropping practices and environments are extremely different except for the rotation: these two sites belong to the so-called ricewheat system of Asia. However this profile, which corresponds to high SHR, SHB, and WB, is represented by 14 fields only and was not directly used in further analytical steps. This step of the analysis therefore allowed us to achieve the characterization of a few-in practice, three- key profiles of injuries due to rice pests. As for the patterns of cropping practices, some of these profiles are shared by very distant sites, while one cluster (IN3) is site-specific.

Two sets of clusters, the patterns of cropping practices and the injury profiles, were thus considered, and the first null hypothesis, $\mathrm{H}_{01}$ : "There is no linkage between cropping practices and injuries" was tested. A high chi-square value was found, and the null hypothesis was rejected $(P<$ $0.0005)$. In addition, both null hypotheses pertaining to independence between actual yield and cropping practices or injury profiles were rejected $(P<0.0005)$. These additional tests further indicate that the clusters for patterns of cropping practices and for injury profiles did capture a relevant amount of information that accounts for yield variation. The very strong linkage between weather patterns and injury profiles may account for relationships between injuries and weather. The equally strong linkage between weather patterns and patterns of cropping practices, on the other hand, suggests that patterns of cropping practices are strongly influenced by weather patterns.

Although considerable caution must be exerted in examining individual contingency tables, some conclusions can be derived from the tests listed in Table 7. These conclusions are drawn from chisquare values and probability levels, and also from the actual pattern of each contingency table (not shown). Among the yieldlimiting factors, drought stress (DS) appears the single most important one. Rather surprisingly, such a straightforward rela- tionship with variation in actual yield is found neither with the amount of fertilizer application (MF) nor with the type of weed control practice (WCP. This must be ascribed to complex relationships among components of the patterns of cropping practices, which need to be addressed as groups using a multivariate approach. The link between pesticide use (IU, HU, and $\mathrm{FU}$ ) and $\mathrm{Y}$ has several interpretations, some of which are not exclusive: (i) pesticides ensure higher yield by suppressing injuries (i.e., there is indeed a yield-protecting effect of pesticides); (ii) pesticide use is associated with other cropping practices that ensure higher yields (i.e., pesticides are associated with production situations where several yield-limiting factors are mitigated, and thus, with higher attainable yields); and (iii) high pesticide use, albeit inefficient, is a reflection of the simultaneous occurrence of both high injuries (and farmer's reactions) and good crop stands (i.e., pesticides are associated with both good production situations - and high attainable yield - and the occurrence of injuries that have no, or marginal, yieldreducing effects). Yield-reducing effects of SHR, BS, NB, and weeds (especially WA) seem prominent from the examination of contingency tables and chi-square tests (Table 7).

Figure 5A shows how strongly injury profiles are associated with patterns of cropping practices: IN1 with PR1, PR2, and PR4; IN3 and IN5 with PR3; IN2 with PR5 and PR6. Such a strong linkage between injury profiles and patterns of cropping practices was found in earlier case studies $(8,25,30 ;$ D. Zhu, Q. Tang, S.

Table 7. Chi-square tests on the effects of yield limiting and yield reducing factors (Y-variables) on variation of actual yield (X-variable)

\begin{tabular}{|c|c|c|c|c|c|}
\hline Variable type & Variable $^{\mathbf{a}}$ & $\chi_{(\mathbf{X}, \mathbf{Y})}^{2}$ & df & $\boldsymbol{P}$ & Remarks and comments derived from examination of contingency tables \\
\hline \multicolumn{6}{|c|}{ Cropping practices (and yield-limiting factors) } \\
\hline & MF & 37.1 & 8 & $<0.0005$ & High MF associated with higher yield than medium or low \\
\hline & FP & 43.9 & 12 & $<0.0005$ & Short or medium FP associated with lower yields than long or extensive FP \\
\hline & WCP & 18.0 & 8 & 0.02 & Herbicide use associated with higher yields than hand weeding \\
\hline & IU & 49.8 & 12 & $<0.0001$ & Medium or high insecticide use associated with higher yields than no insecticide use \\
\hline & HU & 30.8 & 8 & 0.0002 & Low (and not high) HU associated with higher yields than no herbicide use \\
\hline & FU & 34.9 & 4 & $<0.0001$ & Fungicide use associated with higher yields \\
\hline & DS & 65.7 & 8 & $<0.0001$ & Water stress associated with lower yields \\
\hline & WE & 33.0 & 4 & $<0.0001$ & Water excess associated with lower yields \\
\hline & PM & 38.4 & 4 & $<0.0005$ & Transplanting associated with higher yields than direct seeding \\
\hline & $\mathrm{PC}$ & 58.7 & 16 & $<0.0005$ & $\begin{array}{l}\text { Variable yield associated with } \mathrm{PC}=\mathrm{Fal}, \mathrm{Leg}, \text { or Misc. ; higher yields associated with } \\
\mathrm{PC}=\text { Rice }\end{array}$ \\
\hline \multicolumn{6}{|c|}{ Injuries (reducing factors) } \\
\hline & BLB & 17.8 & 8 & 0.02 & High BLB associated with lower yields \\
\hline & SR & 27.6 & 8 & 0.0006 & High SR associated with high (Y4) but not very high (Y5) yields \\
\hline & SHR & 38.6 & 8 & $<0.0001$ & High SHR associated with lower yields \\
\hline & SHB & 15.9 & 8 & 0.04 & High SHB, as well as absence of SHB, associated with low (Y1) yields \\
\hline & BS & 70.9 & 8 & $<0.0001$ & High BS associated with low yields \\
\hline & LB & 40.3 & 8 & $<0.0001$ & High LB associated with either low (Y1) or high (Y5) yields \\
\hline & NB & 24.6 & 8 & 0.002 & High NB associated with low yields \\
\hline & $\mathrm{PH}$ & 18.8 & 8 & 0.02 & High PH, as well as absence of $\mathrm{PH}$, associated with high yields \\
\hline & RWM & 74.5 & 8 & $<0.0001$ & Absence, as well as high, RWM associated with high yields \\
\hline & LF & 29.9 & 8 & 0.0002 & Absence of LF associated with high yields \\
\hline & DH & 18.2 & 8 & 0.02 & High DH associated with low yields \\
\hline & WH & 16.0 & 8 & 0.04 & High WH associated with low yields \\
\hline & WA & 29.9 & 8 & 0.04 & High WA associated with low yields \\
\hline & WB & 60.9 & 8 & $<0.0001$ & High WB associated with low yields, and low WB associated with high yields \\
\hline
\end{tabular}

\footnotetext{
${ }^{a}$ See Table 1 for variable list.
} 
Huang, X. Lin, and S. Savary, unpublished). The present result, however, pertains to a survey across the tropical region of Asia and strongly suggests that earlier conclusions-that patterns of cropping practices are a major determining factor of injury profiles at the site level—also hold true at the regional scale.

A clear path of increasing yield levels is generated when the [clusters of cropping practices $\times$ yield level] contingency table is considered (Fig. 5B). This path is essentially defined on the first (horizontal) axis and cuts across a number of patterns of cropping practices, from PR3 (associated with low yields) to PR5 (low to medium), and to PR1 (high yields). Interestingly, the path takes the direction PR4 (a pattern found in HGZ only), suggesting the association of this pattern with very high yields only. Indeed, all yields under PR4 are categorized in the high (Y4) or very high (Y5)
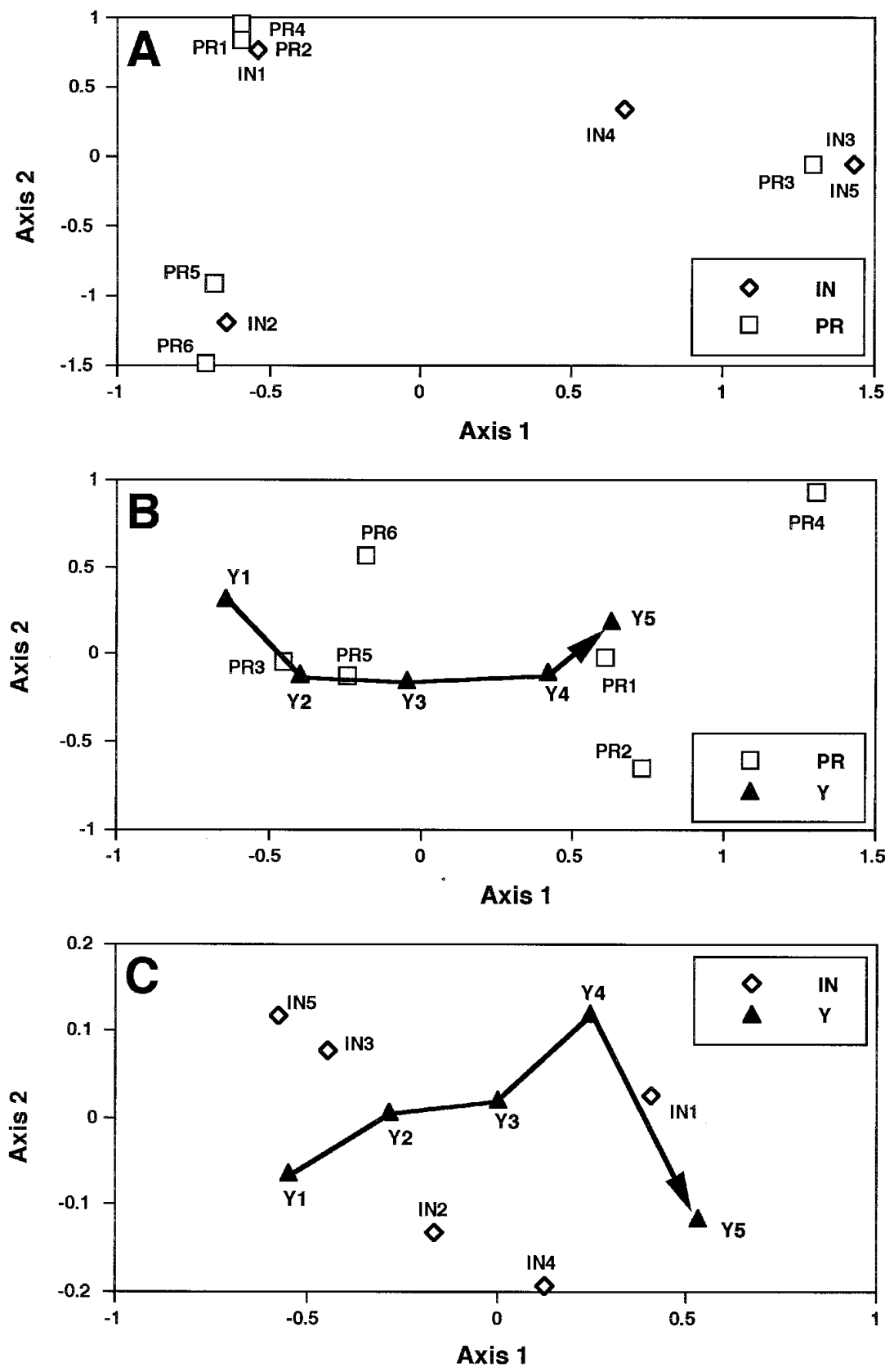

Fig. 5. Three correspondence analyses. Clusters of patterns of cropping practices (PR), clusters of injury profiles (IN), and yield levels (Y) are plotted on the two first axes of each analysis, using a chi-square distance. (A) Correspondence analysis pertaining to the [IN $\times$ PR] contingency table (injury profiles by patterns of cropping practices). (B) Correspondence analysis pertaining to the $[\mathrm{Y} \times$ PR] contingency table (actual yield by patterns of cropping practices). A path of increasing yield levels (Y1 to Y5) is indicated. (C) Correspondence analysis pertaining to the [Y $\times \mathrm{IN}]$ contingency table (actual yield by injury profiles). A path of increasing yield levels (Y1 to Y5) is indicated. In all three analyses, the factorial plane shown (i.e., the two first axes) accounts for more than $75 \%$ of total inertia. yield levels (9.1 and $90.9 \%$ of the fields, respectively).

A well-delineated path is also found when injury profiles and actual yields are considered simultaneously (Fig. 5C). Two differences with Figure 5B should be noticed, however: (i) the path cuts across the entire factorial plane, i.e., depends on both axes, and (ii) yield levels are not associated with any of the plotted injury profiles in particular. By contrast with Figure 5B, Figure $5 \mathrm{C}$ therefore suggests that the relationships between injury profiles and yield levels are indirect. In spite of the high chisquare value of the [injury profiles $\times$ yield level] contingency table, the relationship between the two variables is a complex one, which may involve another, intermediate variable. It is hypothesized that this intermediate variable is the pattern of cropping practices. This interpretation is supported by the strong linkage between patterns of cropping practices and weather patterns, the former (farmers' practices) being strongly influenced by the latter (prevailing climate).

Correspondence analysis using a Burt table (Table 8, Fig. 6) offers a synthetic view of the final results and provides further support to this hypothesis. Reciprocal contributions of axes to describing yield levels are high (Table 8), indicating that this correspondence analysis captures a large fraction of the variation in actual yield levels. The same remark holds true for weather patterns and for most sites (ILO excepted). This analysis involving $\mathrm{PR}$ and IN clusters as active variables thus generates a sound framework from the agronomic (PR), pests (IN), weather (W), and sites standpoints to analyze variation in actual yield. Three main groups of variables are distinguished in Figure 6:

1. PR1, PR2, and PR4, associated with IN1, under weather type W2 in CLUZ and HGZ;

2. PR3, associated with IN3 and IN5, under weather type $\mathrm{W} 3$ in FAIZ;

3. PR5 and PR6, associated with IN2, under weather type W5 and W6 in MD and LAG.

As in the previous correspondence analyses, a path of increasing yield levels is drawn, which moves away from the second group to a direction intermediate between the first and the third groups. The highest yield category (Y5) is located between the first and the third groups, indicating that it is associated to both. Furthermore, Y5 is very close to weather types W4 or W1 (which predominate in HGZ and LAG, or in LAG and CLUZ, respectively), whereas $\mathrm{Y} 1$ is closer to the harsh climate of W3 (FAIZ, Fig. 4A). This last analysis therefore provides additional information pertaining to climate interactions on patterns of cropping practices in influencing yields; that is to say, it offers a view of production situations $(7,23)$ determining yield variation. It would suggest that pat- 
terns of cropping practices prevailing in CLUZ, HGZ, LAG, or MD could lead to even higher yields, should weather types such as W1 (medium to high radiation, especially) or W4 (comparatively low temperatures) prevail.

The mean actual yield estimated from this survey is $4.12 \pm 0.13 \mathrm{t} \mathrm{ha}^{-1}(\mathrm{SE}=$ $0.066 \mathrm{t} \mathrm{ha}^{-1}$ ). This estimate is within the range of currently reported average yield across tropical Asia (about $4 \mathrm{t} \mathrm{ha}^{-1}$; e.g., 13). It is also quite far from the potential yield of modern rice varieties under nearoptimal production situations, which ranges from 8 to $12 \mathrm{t} \mathrm{ha}^{-1}$, whether measured or simulated (13). Our mean yield estimate and its agreement with the literature is suggestive of an adequate sample. It strongly points at the progress that still may be achieved using available technologies. Our results further suggest that much of this progress could be achieved by alleviating some yield-limiting factors of production situations prevailing in tropical Asia, and particularly, improving the water supply to rice crops.

The rejection of $\mathrm{H}_{01}$ provides statistical evidence of the shifts in importance of rice pests (19) with changes in patterns of cropping practices, i.e., changes in patterns of cropping practices may lead to the mitigation or disappearance, as well as to the intensification or appearance, of injuries caused by rice pests. Being based on surveys in farmers' fields, this study does not allow us to rank injury profiles in their yield-reducing effects (26). It does, how- ever, indicate the changes in profiles that are to be expected, and analyses are underway on experimental data (29) to construct such a hierarchy.

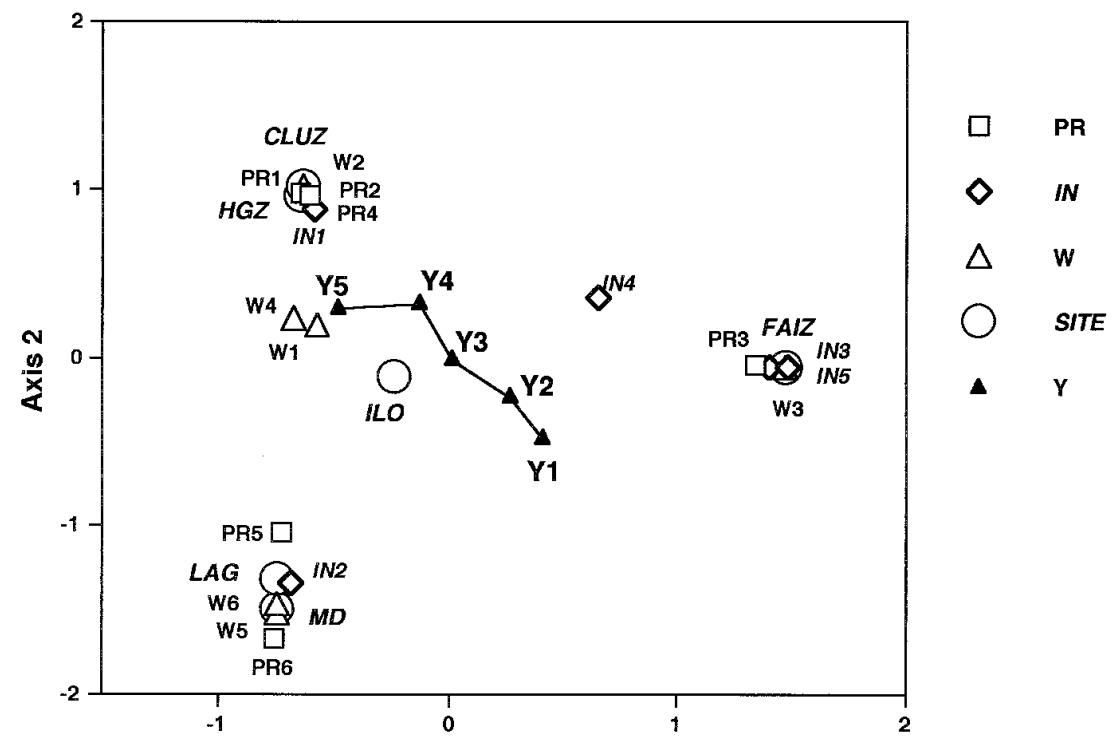

\section{Axis 1}

Fig. 6. Correspondence analysis using a Burt table. A Burt table consists of contingency tables of injury profiles by patterns of cropping practices. Additional variables are weather types (W), sites, and actual yield (Y). A path of increasing yield levels (Y1 to Y5) is indicated. See text and Table 8 for interpretation of the graph.

Table 8. Correspondence analysis: relative weights and contribution to axes

\begin{tabular}{|c|c|c|c|c|c|c|c|}
\hline \multirow[b]{3}{*}{ Classes } & \multirow{3}{*}{$\begin{array}{c}\text { Relative } \\
\text { weight }\end{array}$} & \multicolumn{3}{|c|}{ Axis 1} & \multicolumn{3}{|c|}{ Axis 2} \\
\hline & & \multirow[b]{2}{*}{ Coordinate } & \multicolumn{2}{|c|}{ Contribution } & \multirow[b]{2}{*}{ Coordinate } & \multicolumn{2}{|c|}{ Contribution } \\
\hline & & & To axis & Reciprocal & & To axis & Reciprocal \\
\hline \multicolumn{8}{|l|}{ Variables $^{\mathrm{a}}$} \\
\hline PR1 & 0.187 & -0.639 & 8.34 & 29.36 & 0.969 & 21.49 & 67.44 \\
\hline PR3 & 0.168 & 1.342 & 33.06 & 97.95 & -0.052 & 0.06 & 0.15 \\
\hline PR5 & 0.100 & -0.728 & 5.77 & 18.81 & -1.045 & 13.34 & 38.78 \\
\hline PR6 & 0.042 & -0.753 & 2.61 & 8.18 & -1.679 & 14.52 & 40.64 \\
\hline IN1 & 0.221 & -0.578 & 8.08 & 30.03 & 0.872 & 20.60 & 68.19 \\
\hline IN2 & 0.134 & -0.688 & 6.92 & 20.20 & -1.350 & 29.91 & 77.82 \\
\hline IN3 & 0.148 & 1.479 & 35.23 & 97.98 & -0.066 & 0.07 & 0.19 \\
\hline \multicolumn{8}{|l|}{ Additional classes } \\
\hline W1 & - & -0.567 & - & 85.82 & 0.186 & - & 9.29 \\
\hline W2 & - & -0.636 & - & 27.64 & 1.018 & - & 70.86 \\
\hline W3 & - & 1.473 & - & 99.65 & -0.065 & - & 0.19 \\
\hline W4 & - & -0.669 & - & 77.89 & 0.234 & - & 9.54 \\
\hline W5 & - & -0.745 & - & 16.94 & -1.529 & - & 71.32 \\
\hline W6 & - & -0.745 & - & 20.32 & -1.468 & - & 78.90 \\
\hline PR2 & - & -0.604 & - & 10.38 & 0.965 & - & 26.46 \\
\hline PR4 & - & -0.604 & - & 10.38 & 0.965 & - & 26.46 \\
\hline IN4 & - & 0.649 & - & 19.94 & 0.353 & - & 5.90 \\
\hline IN5 & - & 1.409 & - & 39.75 & -0.057 & - & 0.07 \\
\hline CLUZ & - & -0.638 & - & 30.00 & 0.960 & - & 67.92 \\
\hline FAIZ & - & 1.473 & - & 99.65 & -0.065 & - & 0.19 \\
\hline HGZ & - & -0.633 & - & 27.70 & 1.014 & - & 70.96 \\
\hline ILO & - & -0.238 & - & 6.17 & -0.121 & - & 1.60 \\
\hline LAG & - & -0.740 & - & 16.10 & -0.322 & - & 51.37 \\
\hline MD & - & -0.745 & - & 19.01 & -1.496 & - & 76.52 \\
\hline $\mathrm{Y} 1$ & - & 0.408 & - & 40.38 & -0.469 & - & 53.42 \\
\hline Y2 & - & 0.271 & - & 49.63 & -0.221 & - & 32.96 \\
\hline Y3 & - & 0.018 & - & 1.67 & -0.012 & - & 0.70 \\
\hline Y4 & - & -0.131 & - & 13.75 & 0.319 & - & 81.26 \\
\hline \multirow{2}{*}{$\begin{array}{c}\text { Y5 } \\
\text { Inertia accounted for by axes }\end{array}$} & - & -0.476 & - & 65.47 & 0.302 & - & 26.29 \\
\hline & & $45.1 \%$ & & & $40.2 \%$ & & \\
\hline
\end{tabular}

\footnotetext{
${ }^{\mathrm{a}}$ Columns and row of the Burt table.
} 
This study emphasizes that pest management strategies should be based on patterns of cropping practices, and more broadly, on production situations. It further illustrates how production situations may vary from one field to another in the same site, sometimes within a range of a few meters, owing to variations in farmers' management practices. Developing pest management strategies may thus appear a daunting task. However, this study shows that, whether the scale considered is the individual site or a region such as tropical Asia, common patterns of cropping practices and injury profiles can be determined. The approach outlined here therefore provides an avenue for developing field-specific, yet general, domains for pest management strategies for rice.

The meta-analysis presented here may provide a broad framework on rice pest problems encountered in tropical Asia. The similarities and dissimilarities among sites that this framework highlights may be helpful for multinational resource allocation to research. With respect to diseases, for instance, stem rot and sheath blight appear to be the most common diseases in well-managed crops of Southeast Asia's "rice bowls" typified by PR1; brown spot and sheath rot appear to dominate the disease profile in southern Asia's rice-wheat system (PR3), in combination with many other diseases such as sheath blight and leaf and neck blast. Occurrence of bacterial leaf blight and blast, along with high levels of brown spot, characterize the disease profile where rice is mostly direct-seeded in a monocrop with frequently high input (PR5 and PR6).

\section{ACKNOWLEDGMENTS}

This research was partly funded by the French Ministry of Foreign Affairs, the French Ministry of Research, and a grant from the Rockefeller Foundation. We are grateful to T. W. Mew and K. S. Fischer at IRRI and to R. W. Herdt at the Rockefeller Foundation for their support, and to Nancy Castilla and Orlando Calcetas for assistance in processing and managing data.

\section{LITERATURE CITED}

1. Bailey, R. G. 1996. Ecosystem Geography. Springer-Verlag, New York.

2. Benzécri, J. P. 1973. L'Analyse des Données. Tome 2. L'Analyse des Correspondances. Dunod, Paris.

3. Boote, K. J., Jones, J. W., Mishoe, J. W., and Berger, R. D. 1983. Coupling pests to crop growth simulators to predict yield reductions. Phytopathology 73:1581-1587.

4. Chancellor, T. C. B., Teng, P. S., and Heong, K. L., eds. 1996. Rice tungro disease epidemiology and vector ecology. IRRI Discussion Pap. Ser. 19, Los Baños, Philippines.
5. Cu, R. M., Mew, T. W., Cassman, K. G., and Teng, P. S. 1996. Effect of sheath blight on yield in tropical, intensive rice productions system. Plant Dis. 80:1103-1108.

6. Dagnélie, P. 1973. Théorie et Méthodes Statistiques. Applications Agronomiques. Vol. 2. Presses Agronomiques de Gembloux.

7. De Wit, C. T., and Penning de Vries, W. W. T. 1982. L'analyse des systèmes de production primaires. Pages 275-283 in: La Productivité des Pâturages Sahéliens. W. W. T. Penning de Vries and M. A. Djiteye, eds. Agricultural Research Report 918, Pudoc, Wageningen, Netherlands.

8. Du, P. V., and Savary, S. 1997. A survey of rice constraints in the Mekong delta. Intern. Rice Res. Notes 22:43-44.

9. Elazegui, F. A., Soriano, J., Bandong, J., Estorninos, L., Jonson, I., Teng, P. S., Shepard, B. M., Litsinger, J. A., Moody, K., and Hibino, H. 1990. Methodology used in the IRRI integrated pest survey. Pages 241271 in: Crop Loss Assessment in Rice. IRRI, Los Baños, Philippines.

10. Flinn, J. C., and De Datta, S. K. 1984. Trends in irrigated rice yields under intensive cropping at Philippine research stations. Field Crop Res. 9:1-15.

11. Gibbons, J. D. 1976. Non Parametric Methods for Quantitative Analysis. Holt, Rinehart and Winston, New York.

12. Greenacre, M. J. 1984. Theory and Applications of Correspondence Analysis. Academic Press, London.

13. Greenland, D. J. 1997. The Sustainability of Rice Farming. CABI-IRRI, Wallingford, U.K., Los Baños, Philippines.

14. International Rice Research Institute. 1995. World Rice Statistics 1993-1994. IRRI, Los Baños, Philippines.

15. Lebart, L., Morineau, A., and Fénelon, J. P. 1982. Traitement des Données Statistiques. Méthodes et Programmes. Dunod, Paris.

16. Lebart, L., Morineau, A., and Piron, J. P. 1995. Statistiques Exploratoire Multidimentionnelle. Dunod, Paris.

17. McCool, P. M., Younglove, T., Musselman, R. C., and Teso, R. R. 1986. Plant injury analysis: Contingency tables as an alternative to analyses of variance. Plant Dis. 70:357-360.

18. Mew, T. W. 1991. Disease management in rice. Pages 279-299 in: CRC Handbook of Pest Management in Agriculture. 2nd ed. Vol. III. D. Pimentel and A. A. Hanson, eds. CRC Press, Boca Raton, FL.

19. Mew, T. W. 1992. Management of rice diseases-A future perspective. Pages 54-66 in: Pest Management and the Environment in 2000. A. Aziz, S. A. Kadir, and H. Barlow, eds. CAB International, Wallingford, U.K.

20. Nagarajan, S. 1989. Plant protection problems in rice-wheat rotation system-A perspective. Oryza 26:329-333

21. Ou, S. H. 1987. Rice Diseases. 2nd ed. CAB International, Farnham House, Farnham Royal, Slough, England.

22. Rabbinge, R. 1993. The ecological background of food production. Pages 2-29 in: Crop Protection and Sustainable Agriculture. D. J. Chadwick and J. Marsh, eds. Ciba Foundation Symposium 177. John Wiley \& Sons, Chichester, England.

23. Rabbinge, R. D., and De Wit, C. T. 1989.
Systems, models and simulation. Pages 3-15 in: Simulation and Systems Management in Crop Protection. R. Rabbinge, S. A. Ward, and H. H. Van Laar, eds. Pudoc, Wageningen, Netherlands.

24. Rabbinge, R., and Rijsdijk, F. H. 1981. Disease and crop physiology: A modeller's point of view. Pages 199-220 in: Effects of Disease on the Physiology of the Growing Plant. P. G. Ayres, ed. Cambridge University Press, Cambridge.

25. Savary, S., Elazegui, F. A., Moody, K., and Teng, P. S. 1994. Characterization of rice cropping practices and multiple pest systems in the Philippines. Agric. Syst. 46:385-408.

26. Savary, S. Elazegui, F. A., Pinnschmidt, H. O., and Teng, P. S. 1997. Characterization of rice pest constraints in Asia: An empirical approach. Pages 83-98 in: Applications of Systems Approaches at the Farm and Regional Levels. P. S. Teng et al., eds. Kluwer Academic Publishers, Dordrecht, Netherlands.

27. Savary, S., Elazegui, F. A., and Teng, P. S. 1996. A survey portfolio for the characterization of rice pest constraints. IRRI Discussion Pap. Ser. 18, Los Baños, Philippines.

28. Savary, S., Madden, L. V., Zadoks, J. C., and Klein-Gebbinck, H. W. 1995. Use of categorical information and correspondence analysis in plant disease epidemiology. Adv. Bot. Res. incorporating Adv. Plant Pathol. 21:213-240.

29. Savary, S., Pinnschmidt H. O., Elazegui, F. A., Castilla, N. P., and Teng, P. S. 1997. A new approach to quantify crop losses due to rice pests in varying production situations. IRRI Discussion Pap. Ser. 20. IRRI, Los Baños, Philippines.

30. Savary, S., Srivastava, R. K., Singh, H. M., and Elazegui, F. A. 1997. A characterization of rice pests and quantification of yield losses in the rice-wheat system of India. Crop Prot 16:387-397.

31. Shepard, B. M., Khan, Z. R., Pathak, M. D., and Heinrichs, E. A. 1991. Management of insect pests of rice in Asia. Pages 255-278 in: CRC Handbook of Pest Management in Agriculture. Vol. III. D. Pimentel and A. A. Hanson, eds. CRC Press, Boca Raton, FL.

32. Teng, P. S. 1990. Current knowledge on crop losses in tropical rice. Pages 38-53 in: Crop Loss Assessment in Rice, IRRI, Los Baños, Philippines.

33. Teng, P. S. 1990. Integrated Pest Management in Rice. An Analysis of the Status Quo with Recommendation for Action. Rep. USAID Pestic. Pest Manage. Proj.

34. Teng, P. S., Fischer, K. S., and Hossain, M. 1995. Meeting the food challenges of the 21st century: The role of national and international rice research. Asian J. Trop. Biol. 1:1-21.

35. Teng, P. S., and Yuen, J. E. 1990. Epidemics models: Lessons from plant pathology. Pages 211-220 in: Risk Assessment in Genetic Engineering: Environmental Release of Organisms. M. Levin and H. Strauss, eds. McGraw Hill, New York.

36. Van Ittersum, M. K., and Rabbinge, R. 1997. Concepts in production ecology for analysis and quantification of agricultural input-output combinations. Field Crops Res. 52:197-208.

37. Zadoks, J. C., and Schein, R. D. 1979. Epidemiology and Plant Disease Management. Oxford University Press, New York. 